\title{
LA CONSTRUCCIÓN DE SUBJETIVIDAD POLÍTICA EN LA ESCUELA. UNA EXPERIENCIA EN TRES CENTROS DE SECUNDARIA.
}

\section{THE CONSTRUCTION OF POLITICAL SUBJECTIVITY IN SCHOOL. AN EXPERIENCE IN THREE SECONDARY SCHOOLS}

\author{
Nancy Palacios Mena \\ Facultad de Educación \\ Universidad de los Andes, Colombia \\ n.palaciosm@uniandes.edu.co
}

\section{Cómo citar / citation}

Palacios, N. (2019) "La construcción de subjetividad política en la escuela. Una experiencia en tres centros de secundaria". OBETS. Revista de Ciencias Sociales, 14(1): 145181. doi: 10.14198/OBETS2019.14.1.05

\section{Resumen}

El artículo es el resultado de la lectura comprensiva de los discursos y prácticas en los que se evidencia expresiones de construcción de subjetividad política en los jóvenes estudiantes de tres instituciones educativas en Colombia. Se evidenciaron dos grupos de expresiones: las narraciones de construcción de sí y la interpelación al orden establecido; además de su incidencia sobre el sistema de relaciones entre los actores escolares, se pudo determinar que dichas expresiones permiten comprender las reivindicaciones de los jóvenes estudiantes que pugnan por el reconocimiento político y por la inclusión de sus expectativas dentro de una relectura de la ciudadanía.

Palabras clave: Subjetividad política, educación secundaria, socialización escolar, ciudadanía.

\section{Abstract}

The article is the result of a comprehensive reading of the discourses and practices in which expressions of construction of political subjectivity are evidenced in the young students of three educational institutions in Colombia. 
Two groups of expressions were evidenced: the narratives of self-construction and the interpellation to the established order; in addition to its impact on the system of relations between school actors, it was possible to determine that these expressions allow to understand the demands of young students who struggle for political recognition and for the inclusion of their expectations in a rereading of citizenship.

Key words: Political subjectivity, secondary education, school socialization, citizenship.

\section{Extended abstract}

The article is the result of a comprehensive reading of the discourses and practices in which expressions of construction of political subjectivity are evidenced in young students of three educational institutions in Colombia. Two groups of expressions were evidenced: the narratives of self-construction and the interpellation to the established order. In addition to its impact on the system of relations between school actors, it was possible to determine that these expressions allow the understanding of the demands of young students who struggle for political recognition and for the inclusion of their expectations in a rereading of citizenship.

In the research that motivated this article, a qualitative methodological design was implemented and two techniques of data collection were selected: interview and documentary analysis. The empirical universe of the investigation were three secondary, official and coeducational schools located in the urban zone of three municipalities: Ansermanuevo, Carthage and Pereira in Colombia. The students participating in the research belong to the socioeconomic strata 1, 2, 3 with exceptional cases in stratum 4 and 5 in the institutions of Cartago and Pereira. Fifteen semi-structured interviews were conducted, in which we inquired about variables such as: school and extracurricular socialization spaces, aspects of the daily life of the students that contribute to the constitution of their identity, expressions of search for autonomy, importance that students give to their spaces of socialization, selfconstruction narratives, the ways in which students are recognized and how they want to be recognized, students' stories about life in and out of school, people with whom students have affinity, objects, people, situations valued by students as important and influential in their daily lives. The documents were focused on identifying discourses and practices that gave account of the emergence of configuration of political subjectivity.

The systematization of the interviews and the documents required two stages: transcription and theming. In the first one, the contents of the interviews and documents were written literally. In the second, a matrix was elaborated to organize fragments from each of the sources. These fragments were extracted, classified and codified per their correspondence with one of the variables mentioned above. The analytical framework used to analyze information from these sources was the sociology of experience proposed by François Dubet (2010). For this author the analysis of social experience requires three intellectual operations: isolating the logic of subjectivation from other logics of 
action, understanding the activity of the actor within the logic of subjectivation and analyzing how actors combine and articulate the logic of action, subjectivation socialization and claim of rights.

In the discourses and practices of the students participating in this research, expressions of political subjectivity were evident in two groups. In the first group, self-construction narratives, expressions where the defense of singularity is made and some expressions of autonomy were found. In the second group of expressions, the established order is questioned, perceptions of mismatch between the norms and the exercise of power and critical reflexivity in front of the prevailing order were identified. All these expressions allow a better understanding of the demands of young students who struggle for political recognition and the inclusion of their expectations in a rereading of citizenship.

1. The defense of the singularity

The defense of singularity was marked by the willingness to have a personal style, through a different way of presenting the body, of fixing it, embellishing it, and even transforming it, under the justification of wanting to be unique. The analysis of students' manifestations implies an understanding of the body in its complexity, as a soma, as a biological constant and as a cultural construct. The continuous appearance of the defense of a personal style, always linked with the way of presenting the body, is framed in the contemporary social and cultural changes that have generated changes in the lifestyle and practices of each generation group. "The establishment and / or renewal of customs is expressed in the somatic cultures of the time, so the context in which students are is essential to account for the senses and uses that are configured in and from their bodies.

2. Expressions of autonomy

The defense of personal autonomy was the second group of expressions that evidenced the construction of subjectivity in the participants of the study. One of the ways in which these young people express that they have acquired autonomy is their way of acting or expressing themselves in school.

The opinions and actions exposed by students allow us to infer a process of redefinition and significance between social demands, educational practices and conditions imposed by educational institutions. The processes of subjectivation go through the recovery of autonomy, understood as the capacity to think for oneself without ignoring the other, and to recognize, create and dispose in practice the principles that guide life.

Student discourses emphasize the importance of change, justify the actions of young people motivated by the desire for transformation, and highlight the importance that adults, both in their family and at school, also change their minds. This change arises as a necessity, as a duty to coexist and understand the world of students. The content and the tone of some of the requests made by them -in the context of a judicial action such as guardianship or a right of petition or in an informal note, a complaint to improve the school- show how expressions of autonomy emerge. 
3. Perception of mismatch or fracture of the exercise of power and norms In addition to the defense of singularity and expressions of autonomy, another expression identified in the construction of political subjectivities in students was the perception of mismatch between the exercise of power and norms. This mismatch was evident in two manifestations: nonconformity with the exercise of power and the normative system, and an explicit desire for changes in these two aspects.

4. Critical reflexivity to the prevailing order

The fourth expression of configuration of subjectivity that was identified is critical reflexivity to the prevailing order, understood as those discourses and practices where students criticize the school order and make proposals. The critical reflexivity that evidences the actions of the students before the prevailing order in the schools, is read as political action, because it implies young people questioning the exercise of the power of the school authorities. Students show a configuration of political subjectivity when they demonstrate willingness to act, to be recognized, when they oppose the logic of their own school to the logic of their own production, when their acts and speeches demonstrate the desire to create a personal history, when they act on themselves to build their experience and in that experience they acquire the ability to question their daily lives. The data collected allowed us to observe the emergence of processes of subjectivation when students demonstrated their awareness of the world and themselves, with feelings of freedom that make them distance themselves from the established natural order, with capacity for conviction, criticism and autonomy.

The processes of subjectivation or construction of political subjectivity of schoolchildren are an instance of re-signification and of material and symbolic appropriation that takes place in socialization spaces. For this reason, in this study the understanding of the subjectivity production of secondary school students involved considering at least some aspects of their personal history and their interactions with the context.

\section{Introducción}

El artículo es uno de los resultados de un estudio en tres instituciones educativas de secundaria, tiene como como objetivos analizar discursos y prácticas en los que se evidencia expresiones de construcción de subjetividad política en los jóvenes estudiantes de tres instituciones educativas en Colombia, y conceptualizar la reivindicación de derechos de los jóvenes en la escuela secundaria como parte de la construcción de su subjetividad política.

El trabajo se realizó entre el 2014 y el 2016 en tres centros mixtos y oficiales de los municipios de Ansermanuevo, Cartago y Pereira en Colombia. La investigación se fundamentó teóricamente desde la perspectiva de la Sociología de la experiencia propuesta por Dubet (2011); la noción de experiencia hace 
referencia a prácticas individuales o colectivas, orientadas por principios heterogéneos o diversos, es decir, acciones en las cuales los individuos no siguen una misma lógica; hoy, pueden exigir que se acabe una agremiación por considerarla explotadora y violatoria de algunos derechos, y mañana pueden querer su continuidad porque representa la oportunidad de mantener lazos afectivos dentro de un grupo. La experiencia social es definida como una combinación de lógicas de acción cuyo sentido es otorgado por los propios individuos; es una combinación de elementos cuya unidad resulta de la capacidad política de los actores; así mismo, la experiencia social puede concebirse como la manera en que los actores articulan lógicas de acción con el fin de tener el mayor dominio posible de sus vivencias, de sus interacciones en dicha experiencia (Dubet, 2011).

La relación entre la postura teórica de Dubet y la construcción de subjetividad juvenil se da en dos sentidos. Por un lado, los cambios que se observaron empíricamente en las relaciones entre los actores escolares y en la vida de la escuela en general, requirieron de abordajes teóricos diferentes a los que han hecho énfasis en el poder y la dominación; fue necesario un marco analítico como el propuesto por Dubet en su reflexión sobre las instituciones heredadas de la modernidad y su declive, puesto que dichas reflexiones si ponderan las posibilidades y las capacidades de los actores para cuestionar su cotidianidad y contribuir a transformarla.

En consecuencia, con lo anterior, y teniendo como punto de partida otros trabajos como el de Alvarado, Patiño y Ospina (2012), la indagación sobre los procesos de subjetivación de los estudiantes de los tres colegios se llevó a cabo teniendo en cuenta los procesos de formación y socialización. Así, el artículo puede ser leído como un ejercicio de visibilización y enunciación de los estudiantes como sujetos sociales activos en las dinámicas de configuración de acciones políticas. Además, es un reconocimiento a su participación en la construcción de otras lógicas de poder. Porque si bien no se puede plantear que nuestras escuelas se han convertido en espacios democráticos caracterizados por relaciones horizontales entres sus miembros, sí pudieron encontrarse discursos que cuestionan el ejercicio del poder, así como prácticas tendientes a transformarlas.

\section{Escuela y subjetividad política}

Siguiendo la línea de Imaz (2011), este artículo sobre la vida escolar tiene un enfoque de lo social que incorpora la categoría subjetividad individual y colectiva de los sujetos en la comprensión de sus acciones e interacciones. Desde este enfoque, "incorporar la experiencia, expectativas y acciones de los actores sociales, significa reconocer que la vida social, su producción, reproducción 
son el resultado de la interacción de sujetos activos capaces de modificar reflexivamente su conducta" (Imaz, 2011, p.11). En un trabajo en Argentina TentiFanfani (2008) subraya que para comprender la contribución de la escuela a la conformación de las subjetividades es preciso analizarla, en el marco de las relaciones que mantiene con otras agencias de socialización, en especial la familia, los medios de comunicación y los consumos culturales masivos, las iglesias, etcétera.

La subjetividad es una categoría que ha venido tomando fuerza en el marco de los debates contemporáneos sobre construcción de ciudadanía democracia y participación política. Para Sabucedo (1996) "la subjetividad es un proceso de configuración política del ser humano a través de los procesos de socialización" (p.347) y para Guattari (1998) "integra el conocimiento, las construcciones simbólicas e imaginarias de los saberes que entretejen lo simbólico, lo social y lo singular para la construcción de la realidad" (p. 87). Estos autores coinciden en el contenido político de los procesos de subjetivación, entendida en el marco de este trabajo como un proceso en el que el individuo empieza a actuar de manera reflexiva sobre sí mismo y sobre los entornos en los que interactúa.

Para Sousa Santos (1998), la configuración de la subjetividad es un espacio de construcción de sentido político sobre el cual los sujetos construyen realidades posibles o transforman lo existente. Desde estas posturas, en la construcción de subjetividad hay que resaltar el desarrollo de la capacidad de sentir, pensar, expresar y actuar políticamente desde lo individual y lo colectivo, es decir, la adquisición de una conciencia política, así como la preponderancia que en este proceso tiene la socialización de los individuos en todos los ámbitos sociales en los que se desenvuelven (Palacios y Herrera, 2013; Palacios, 2017).

Desde la postura de Alvarado, Ospina, Botero y Muñoz (2008), la subjetivación es un proceso de expresión y expansión del sujeto histórico social y político que solo puede darse entre el nosotros en tramas complejas de intersubjetividad. En línea con lo anterior, hay que indicar que en la lectura de la escuela que subyace a este artículo, ésta es considerada como un escenario en el cual los estudiantes son capaces de desplegar su subjetividad cuando se configuran como sujetos históricos, sociales y culturales y construyen sus universos de sentido desde sus experiencias.

Sobre la construcción de subjetividades en jóvenes estudiantes, el trabajo de Domínguez (2008) indica que dichas subjetividades se configuran a partir de relaciones intersubjetivas en un contexto social y cultural, a través de sucesivas socializaciones y resocializaciones que permiten evaluar las pautas introyectadas por la sociedad y autoafirmarse individual y colectivamente como generación. Los datos que se han analizado en este artículo nos permiten sugerir que las acciones de reivindicación de derechos individuales y colectivas de los estudiantes son experiencias que constituyen subjetividades que se expresan en tramas de sentido, y entretejen prácticas políticas en la cultura y prácticas 
culturales en la política, en las nuevas maneras de aparecer en el mundo (Alvarado, Botero y Ospina 2010).

De esta forma, la formación de subjetividad política en jóvenes "implica la formación de ciudadanía, el crear las oportunidades y las condiciones para que los jóvenes puedan reconocerse como protagonistas de su propia historia, capaces de pensar, e interactuar con otros en la construcción de proyectos colectivos orientados al bien común con espíritu crítico y capacidad de autorreflexión" (Alvarado, Ospina, Botero y Muñoz, 2008, p. 30). Dicha subjetividad como emergente de las distintas realidades sociales- es consecuencia y condición de un proceso de construcción individual y social que, a partir de inserciones sociales específicas, determina la forma particular y singular en que un individuo percibe, interpreta y da sentido a su realidad, interioriza un sistema de valores y organiza su vida y su acción personal. Domínguez (2008).

\section{Metodología}

El universo empírico de la investigación fueron tres establecimientos educativos de secundaria, oficiales, mixtos, ubicados en la zona urbana de tres municipios: Ansermanuevo, Cartago y Pereira en los departamentos del Valle del Cauca y Risaralda en Colombia (ver mapa). Los estudiantes participantes en la investigación pertenecen a los estratos socioeconómicos 1, 2, 3 con unos casos excepcionales en el estrato 4 y 5 en las instituciones de Cartago y Pereira ${ }^{1}$.

${ }^{1}$ La estratificación socioeconómica es una clasificación en estratos de los inmuebles residenciales que deben recibir servicios públicos. Se realiza principalmente para cobrar de manera diferencial por estratos los servicios públicos domiciliarios permitiendo asignar subsidios y cobrar contribuciones en esta área. De esta manera, quienes tienen más capacidad económica pagan más por los servicios públicos y contribuyen para que los estratos bajos puedan pagar sus facturas. La estratificación social también es utilizada para orientar la planeación de la inversión pública; realizar programas sociales como expansión y mejoramiento de infraestructura de servicios públicos y vías, salud y saneamiento, y servicios educativos y recreativos en las zonas que más lo requieran; cobrar tarifas de impuesto predial diferentes por estrato y orientar el ordenamiento territorial (DANE, 2016). 


\section{Mapa $\mathrm{N}^{\circ} 1$. Ubicación de los colegios donde se realizó la investigación}

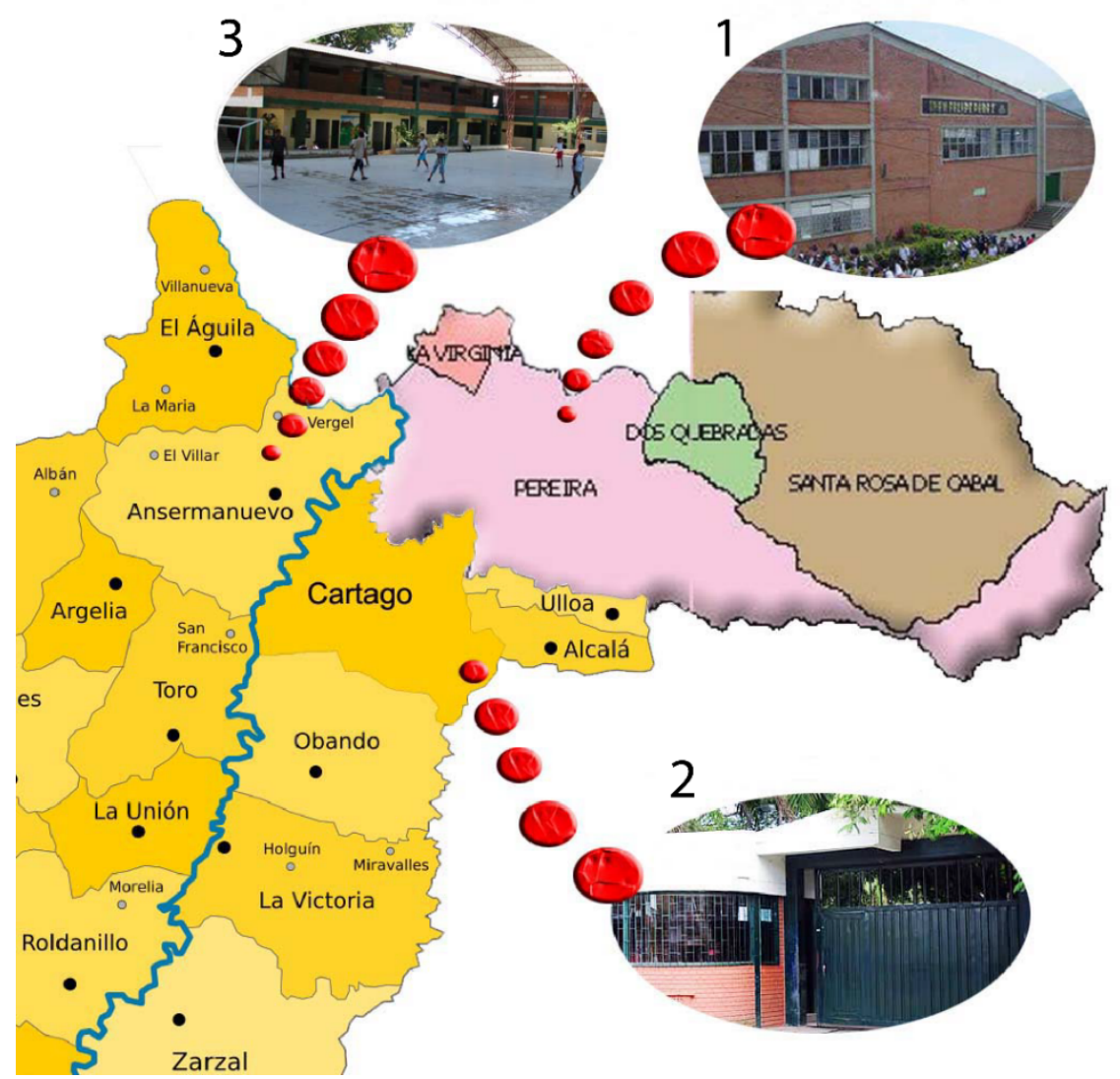

Instituto 1: ubicado en el barrio el Jardín de la ciudad de Pereira, es una institución educativa mixta de carácter oficial que alberga aproximadamente a 3.000 estudiantes de los grados $6^{\circ}$ a $11^{\circ}$. También hace parte de la institución educativa la sede Camilo Torres, en la que se atiende a niños de preescolar y primaria. El colegio fue fundado en 1.972 y lleva su nombre en honor del escritor boyacense Felipe Pérez. Aunque está en una ubicación de estrato 5, presta el servicio educativo principalmente a estudiantes de los estratos 1,2 y 3 , con algunas excepciones de estudiantes de estratos 4 y 5 .

Instituto 2: es un Instituto oficial, mixto, ubicado en la zona urbana del municipio de Cartago, Valle del Cauca. Hace parte de una institución educativa que tiene otras tres sedes de preescolar y primaria: Antonio José de Sucre, Paulina Balcázar y Roberto Castaño, que albergan aproximadamente a 2.500 estudiantes. Según un diagnóstico consultado en la página Web del establecimiento, la institución educativa Académico cuenta con una población 
estudiantil y familiar proveniente de las zonas pobres de la ciudad de Cartago; el 94\% pertenecen a los estratos 1, 2, 3 y 4 , y el 6\% restante a los estratos 5 y 6 . El Colegio Nacional Académico fue uno de los fundados por decreto por Francisco de Paula Santander en 1.839. En la actualidad presta sus servicios bajo la modalidad académica con énfasis en tecnología e informática.

Instituto 3: fundado hace 60 años, hace parte de una institución educativa de 11 sedes que lleva el mismo nombre. Es el único colegio oficial del casco urbano del municipio de Ansermanuevo, Valle del Cauca, y alberga al 97\% de los estudiantes de bachillerato de la cabecera municipal -950 individuos, aproximadamente-. Es un colegio mixto y de modalidad académica. Por ser el único colegio oficial, los estudiantes que reciben el servicio educativo pertenecen a los 3 estratos del municipio.

Se utilizó un diseño metodológico cualitativo que privilegio dos técnicas de recolección de información, la entrevista y el análisis documental. Se realizaron 15 entrevistas semiestructuradas en las cuales se indagó sobre variables como: espacios de socialización escolares y extraescolares, aspectos de la vida cotidiana de los estudiantes que aportan a la constitución de su identidad, expresiones de búsqueda de autonomía, importancia que los alumnos dan a sus espacios de socialización, narraciones de construcción de sí, las maneras cómo se reconocen y cómo quieren ser reconocidos los estudiantes, entrevistas al alumnado sobre la vida en el colegio y fuera de él, personas con quien los estudiantes tienen afinidad, objetos, personas, situaciones valoradas por los alumnos como importantes e influyentes en su cotidianidad.

Los documentos analizados fueron: derechos de petición, quejas, apelaciones, denuncias, los periódicos escolares y el libro en el que los profesores describen el desempeño académico y comportamiento de los estudiantes denominado "observador del alumno". En dichos documentos interesaba identificar discursos y prácticas que dieran cuenta de la emergencia de configuración de la subjetividad política. La sistematización de las entrevistas y los documentos requirió dos etapas, la primera de transcripción y la segunda de tematización. En la primera se escribió literalmente el contenido de las entrevistas y de los documentos, en la segunda se elaboró una matriz con fragmentos de cada una de las fuentes. Dichos fragmentos fueron extraídos, clasificados y codificados según su correspondencia con una de las variables ya mencionadas.

El marco analítico con que se analizó la información procedente de las fuentes citadas, fue el de la sociología de la experiencia propuesto por François Dubet (2010). Para este autor el análisis de la experiencia social requiere tres operaciones intelectuales esenciales, que son presentadas en la figural. 


\section{Gráfico 1. Modelo de análisis de la experiencia social.}

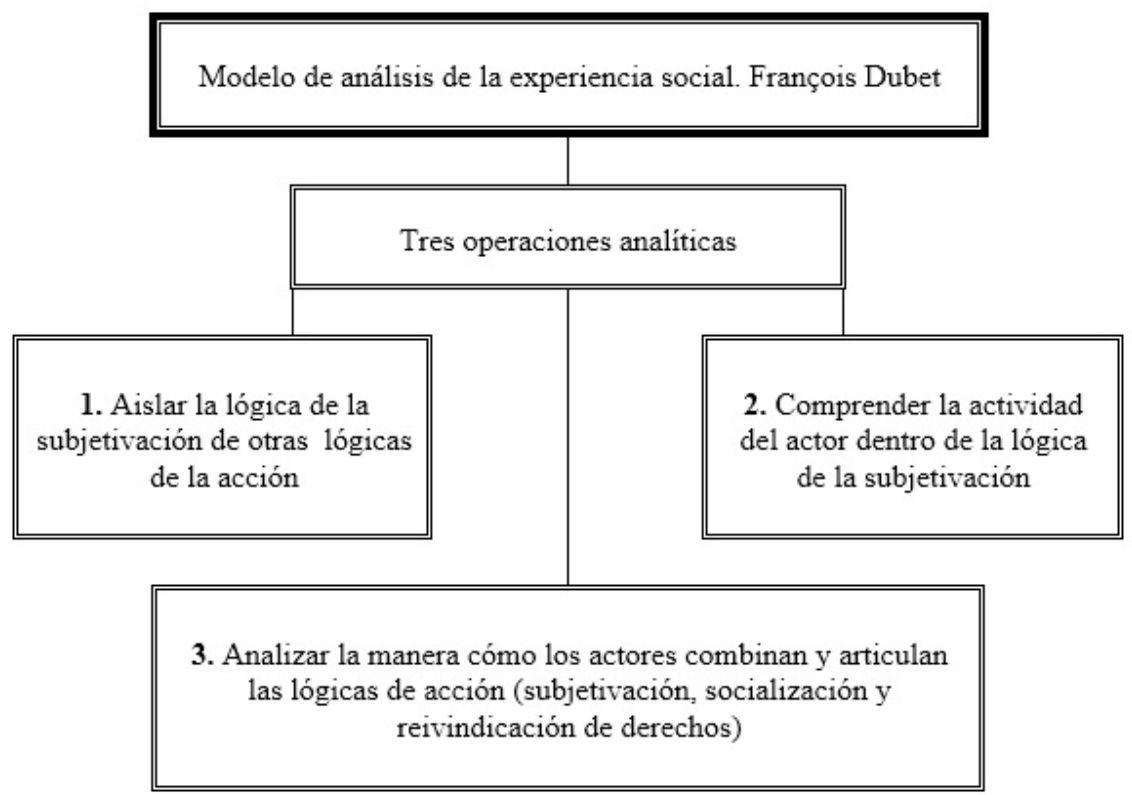

Fuente: Elaboración propia a partir de Dubet (2010:100)

El procedimiento de aplicación del modelo analítico de Dubet (figural) fue el siguiente: en la primera parte se identificaron los discursos y las prácticas de los estudiantes que daban cuenta de la configuración de procesos de subjetivación; en un segundo momento se categorizaron y agruparon dichos discursos y prácticas de subjetivación haciendo énfasis en su naturaleza, características y formas de expresión; finalmente se estableció la manera como los jóvenes estudiantes articulan los procesos de subjetivación con la socialización y la reivindicación de derechos.

También fueron muy valiosos otros datos que llegaron inesperadamente a la investigación, como algunos mensajes anónimos que son dejados debajo de la puerta de uno de los rectores. Hay que recordar que, como apunta González (2012), la subjetividad se configura en una dimensión discursiva, representacional y emocional, que integra los desdoblamientos y consecuencias de procesos que se desarrollan en un nivel macrosocial, con los que ocurren a nivel microsocial, en la familia, en la escuela, en el barrio, y las múltiples y móviles configuraciones subjetivas de los sistemas cotidianos de relación en todas las esferas de la vida 


\section{Resultados y discusión}

Se pudo establecer que la subjetivación se produce en los ámbitos de socialización de los alumnos, y se evidenciaron dos grupos de expresiones: las narraciones de construcción de sí y la interpelación al orden establecido. En el primer grupo se identificaron dos expresiones: la defensa de la singularidad y las expresiones de autonomía. En el segundo también se identificaron dos expresiones: la reflexividad crítica a la institución escolar, y los desajustes y las fracturas en el ejercicio del poder y las normas. Las cuatro expresiones que se identificaron develan distintas formas de construcción de subjetividad política y su incidencia sobre lo político en la escuela. Estas expresiones permiten comprender mejor las reivindicaciones de los jóvenes estudiantes que pugnan por el reconocimiento político y por la inclusión de sus expectativas dentro de una relectura de la ciudadanía.

\section{Gráfico 2. Construcción de subjetividades en la escuela secundaria}

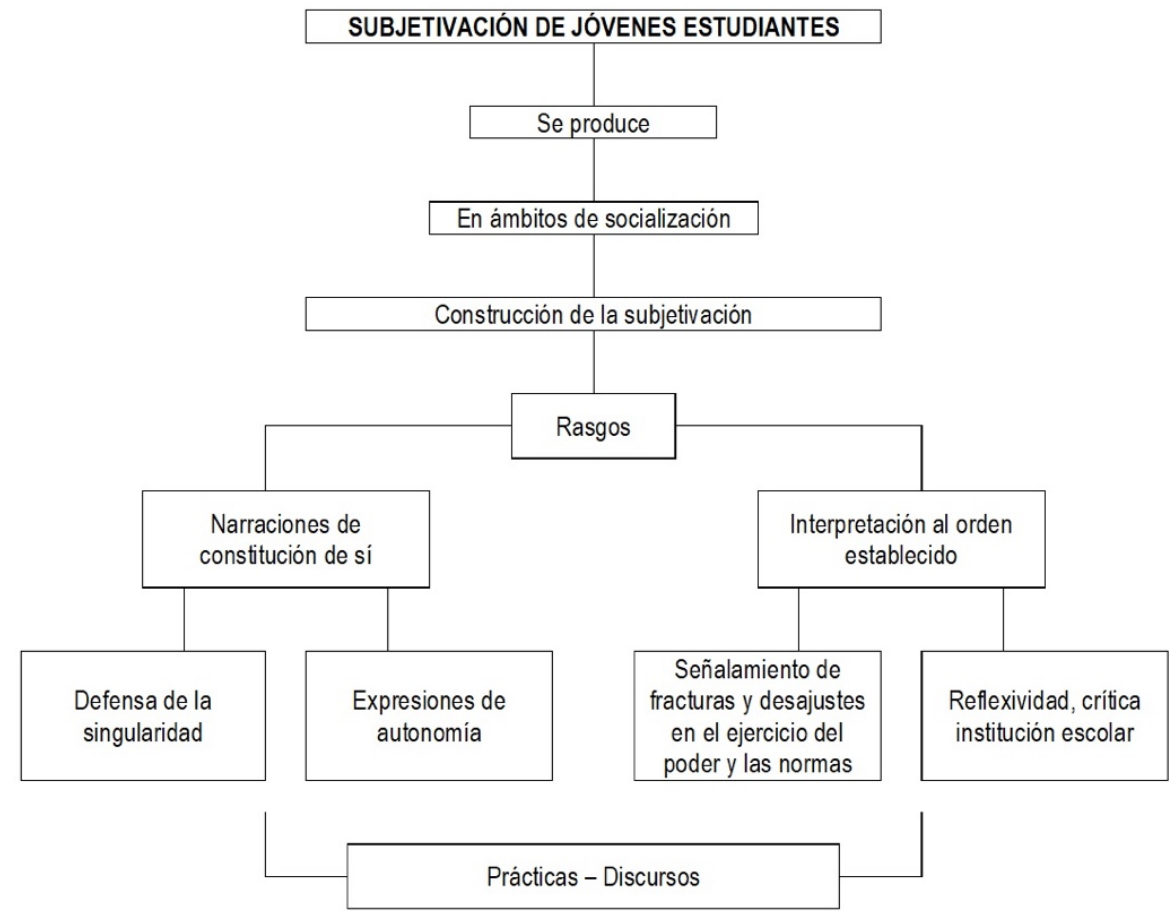

A continuación, se presenta cada una de las expresiones que evidencian la construcción de subjetividades políticas de los estudiantes con los que se compartió en la investigación. 


\section{Narraciones de constitución de sí}

\section{La defensa de la singularidad}

Con este estudio se pudo subrayar un argumento con el que han concluido varios trabajos sobre las trayectorias juveniles y la escuela en los últimos años: la gran motivación y significación que los jóvenes estudiantes encuentran en el cuerpo. En la investigación que da origen al artículo, la defensa de lo singular estuvo marcada por la defensa de un estilo personal, por una forma de presentar el cuerpo, de arreglarlo, embellecerlo e incluso transformarlo, todo bajo la justificación de querer ser único. La lectura de las manifestaciones de los alumnos implica una comprensión del cuerpo en su complejidad, como soma, como constante biológica y como constructo cultural (Díaz, 2002.).

Uno de los estudiantes que se hizo una intervención en el cuerpo explica así la gran importancia que tiene para él la adquisición de un estilo personal propio:

Me puse las expansiones por esa fuerza de ser yo, las ganas de ser uno mismo primero que todo, pues cuando uno se las empieza a hacer es uno el que las está haciendo, aunque hayan muchas personas que se lo quieran prohibir y etcétera, son cosas que uno quiere, eso es lo primero, porque si uno desea algo obviamente hay que cumplirlo, si uno sabe que es bueno o es malo de allí ya parten otras cosas, pero si uno sabe que si es algo bueno y a nadie le está haciendo daño no hay por qué dejarlo de hacer y eso fue lo primero que yo pensé, no hay por qué no hacérnoslas, si hubiera una razón en verdad que dijera huy este muchacho cómo se va a hacer eso, por qué se lo va a hacer, ahí sí uno piensa, no, las hagamos [sic], pero una cuestión que a nadie afecta, es solo el cuerpo, mi cuerpo, entonces no me da como para no hacérmelas, esa fue como la percepción (Entrevista 4)

El estudiante defiende la idea de querer ser diferente, dice darle poca importancia a quienes no respetan la decisión personal de arreglarse y verse como quiera, y valora la facultad de la persona de hacer todo lo que quiera, siempre y cuando sus acciones no le hagan daño a nadie. Muestra su preferencia por pertenecer a una comunidad de gusto musical donde se siente completamente aceptado y no se le cuestiona. El caso de este estudiante fue llamativo, porque si bien hace una fuerte defensa del derecho a ser singular, a no parecerse a los demás, las expresiones del colectivo del cual hace parte y los mismos objetos y accesorios que usa pueden entenderse también como un resultado de las nuevas dinámicas del consumo movidas por el capital, que cada día seducen más a los jóvenes. Autores como Chul-Han (2014), Deleuze (1990), Benjamin 
(1992), han planteado que pareciera que en muchos jóvenes la defensa de la singularidad puede apoyarse en mecanismos provistos por el poder y la dominación que ejerce el capitalismo en nuestras formas de vida, sin que necesariamente nos percatemos de que es así.

Para Cabra (2010), el cuerpo joven reside en una juventud supremamente diversa que pareciera debatirse permanentemente entre la enajenación y la subjetivación. El trabajo corporal implica ingentes esfuerzos del sujeto por configurar en su propia piel, en su imagen, una subjetividad auténtica que evidencia su esfuerzo de singularidad, justo en un mundo de ofertas de repetición, de homogenización encubierta de variaciones. Pero, al mismo tiempo, el esfuerzo de integración a la sociedad, de hacerse un lugar en los entramados sociales, deviene en complicadas mediaciones estéticas que inscriben la búsqueda de mismidad. Se trata de una apariencia que dé cuenta de uno mismo, sin ubicarlo en los límites de lo que en diferentes contextos se considere extravagante.

Hay otro grupo de entrevistas en el que no prima tanto el interés por diferenciarse de la mayoría, sino una defensa del gusto personal: llevar el cabello largo o las prendas de vestir de una determinada manera, porque agrada, porque produce placer y comodidad:

Para mí es importante el cabello porque me gusta, me gusta sentir el cabello que me llega hasta el cuello, que lo puedo doblar así (hace gesto); entonces, digamos para el tipo, el amigo, el compañero que tenga expansión, él se siente bien así. No es porque, cómo decirlo, no es porque él le hayan dicho [sic] no, es que usted hágase esto porque tal, porque cada cual tiene sus gustos, claro, cada cual tiene su gusto, este es mi gusto, este es el gusto de él. Porque yo me siento bien así, y de verdad no creo que vaya a cambiar algo en que me corte el cabello, si sigo siendo un estudiante más que quiere estudiar. Yo creo que es poco el interés colectivo, porque eso va en cada quien; digamos en el colegio, se ha convertido... digamos más en una sociedad que en una comunidad, porque ahora ya cada cual, cada individuo busca su objetivo. (Entrevista 5)

Yo me siento bien con mi cabello, no es que yo voy a modelar como dicen algunos, es que a mí me gusta verme bonito, me gusta verme bien y yo me siento bien pues con el cabello largo, ¿si me entiende? También me maquillo allí un poquitico. Pues la verdad nosotros los jóvenes, o por lo menos yo, me siento mejor con pantalón más apretado a mi pierna porque pues, yo me veo bien, a mí me gusta verme bien, así sea estudiando me gusta verme bien y pues, eso es; algunos critican y hasta insultan a los que somos gay porque nos arreglamos y queremos estar siempre bien; dicen que venimos a buscar pareja aquí, eso es mentira, aquí ningún gay busca pareja, son niñitos muy inmaduros, uno su pareja la tiene afuera. (Entrevista 6)

Para justificar lo importante que es para los estudiantes llevar su cabello largo en el colegio y vestirse como se desea, acuden a varios argumentos, además del gusto personal: la poca influencia que su presentación personal tiene 
en sus actividades estudiantiles, y el hecho de ver el colegio como una sociedad pequeña, que además es transitoria, en la que cada uno tiene sus intereses y es común el deseo de aprender y de obtener el título de bachiller, y en esto nada tiene que ver los accesorios que se llevan. Estos gustos juveniles han sido leídos por algunos autores como la defensa de un proceso de "juvenilización" en el que han incurrido antes muchos adultos: hace unas décadas eran claramente diferenciables los estilos juveniles de los demás. Estas diferencias se han ido borrando con los años, y al llegar a la edad adulta los antes jóvenes adoptan el estilo de los nuevos jóvenes, que a su vez adoptan otras formas de diferenciación, algunos estilos que los diferencien de las generaciones que los preceden. Este aspecto se ha convertido en un asunto muy importante de la vida, al que se dedican muchas energías, y en el que se pone a prueba una gran capacidad para innovar y para imaginar.

Según Urresti (2008), la "juvenilización" es el resultado de una sociedad que invierte crecientes recursos en la lucha contra el paso del tiempo y contra las marcas que este deja en el cuerpo. Tanto en mujeres como en hombres, esta tendencia se ha afianzado entre un número creciente de adultos, quienes, con el fin de mantenerse jóvenes, comprometen enormes energías y recursos. En el terreno del aspecto físico hay una generalización de la juventud como signo exterior, como forma de presentación ante los otros, a la que contribuyen el mercado de la indumentaria, las actividades de tiempo libre, las ofertas de esparcimiento y de turismo.

Además de las justificaciones del gusto personal, en la última entrevista el estudiante introduce el elemento de la preferencia sexual. Considera que "verse bonito" es un componente de su condición sexual, pero enfatiza en que el empeño que pone a su arreglo personal no está orientado a agradar a nadie, lo hace para verse y sentirse bien consigo mismo. En la parte argumentativa de una acción de tutela para que el estudiante sea reincorporado al colegio, su mamá expresa lo siguiente:

Hace poco mi hijo descubrió que su personalidad era la de ser gay y por ende es su deseo llevar el cabello largo, y el Rector del colegio ha querido sacarlo del colegio por eso, por eso hemos reclamado y luchado que cese la violación de su derecho al libre desarrollo de la personalidad, generándose con ello conflictos; el Rector no quiere dejarlo ni siquiera que use un poco de base (maquillaje) en la cara como es su costumbre. (Acción de tutela estudiante $9^{\circ}$ )

Todas las acciones que el estudiante llevó a cabo con el apoyo de su madre, solicitando el acompañamiento y veeduría de la Personería Municipal, la interposición de tutelas en primera y en segunda instancia y la presentación de su caso en una entrevista televisiva, demuestran que este estudiante tiene una fiel convicción de la legitimidad de los derechos que está defendiendo. Para Cabra (2010), la escuela es el escenario de transformaciones sociales que van desde el 
movimiento transgénico hasta las recomposiciones estéticas de las culturas juveniles, pasando por las diversidades sexuales. Según ella, aunque históricamente la escuela ha intentado contener y reprimir la emergencia de subjetividades que oscilan entre la potencia y la fragilidad, hoy le resulta difícil hacerlo, porque estas no están detenidas ni menguadas en su posibilidad de acción.

Dentro del contexto de esta investigación, el hecho de que algunos estudiantes materialicen su intención de transformar el uniforme y se presenten con su innovación a la institución educativa es una clara señal de libertad, de procesos de subjetivación. Durante el estudio se tuvo la oportunidad de dialogar con varios estudiantes que un día decidieron hacerle algún cambio a su uniforme y portarlo sin temor de las prohibiciones de las autoridades escolares.

El primer caso es el de una estudiante de grado $8^{\circ}$ que decide agregarle a su falda del uniforme varias franjas de pedrería en murano:

Le puse las piedritas a la falda porque me parecía atractivo. La hacía diferente a las demás, me decían iqué bacana y qué bonita! Aunque la coordinadora me dijo que le quitara las piedras, no se las quité porque no, porque yo la compré, es mi falda y no se las quito, yo a mi ropa y a mi uniforme le pongo y le quito lo que quiera. (Entrevista 9)

Esta estudiante destaca tres aspectos: su deseo de verse bien, de sentirse bonita, lo bien que la hicieron sentir los comentarios de aceptación de otros compañeros y la facultad de llevar sus prendas de vestir con libertad, así esta prenda haga parte del universo normativo institucional del colegio (imagen 1). 
Imagen 1. Autonomía en el diseño del uniforme: franjas de pedrería en murano. Foto de la autora

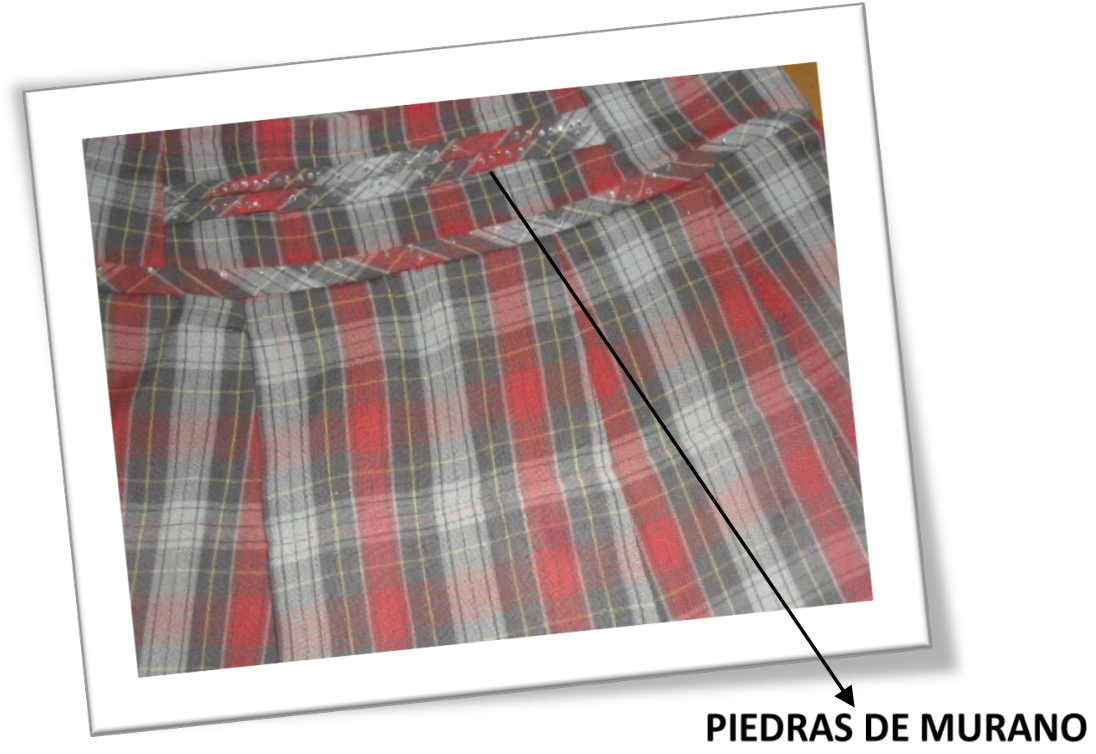

El segundo caso es el de tres estudiantes de grado $10^{\circ}$ quienes decidieron mandar a hacer la camiseta de su uniforme sin cuello, por diferentes razones:

Yo mandé a hacer mi uniforme diferente porque yo me siento más relajado así, ese cuello me estresa y yo lo compré así, yo dije me lo hacen sin cuello y a mí me lo hicieron. Es que lo más importante es sentirse mejor, sentirse bien y además uno viene a estudiar, no viene a nada más sino a estudiar. (Entrevista 11 estudiante $10^{\circ}$ )

Yo la traje fue en la clausura de 9º yo la mandé hacer, porque ese cuello a veces a uno lo estresa mucho, no lo deja como que tener como aire. Cuando a mí la coordinadora me llamó, le dije yo, es que a mí este buzo no me impide aprender y estudiar, pregunte que yo aquí no tengo ningún problema. (Entrevista 11, estudiante $10^{\circ}$ )

No pues yo lo hice porque la verdad me quería sentir diferente y pues ese cuellito hay que estárselo acomodando, y que no, entonces como que quería cambiar. Ser diferente es bueno, de todas maneras, uno siempre que, con lo mismo no, y uno briega a hacer las cosas con lo que uno se pueda sentir más cómodo. (Entrevista 11 , estudiante $10^{\circ}$ )

Los tres estudiantes que hicieron cambios en el uniforme también comparten el gusto por sentirse bien, resaltan la comodidad y el deseo de sentirse diferentes, pero también destacan que su diferencia en la presentación personal no interfiere en su condición de estudiante (imagen 2). 
Imagen 2. Autonomía en el diseño del uniforme: camisa sin cuello Fotos de la autora

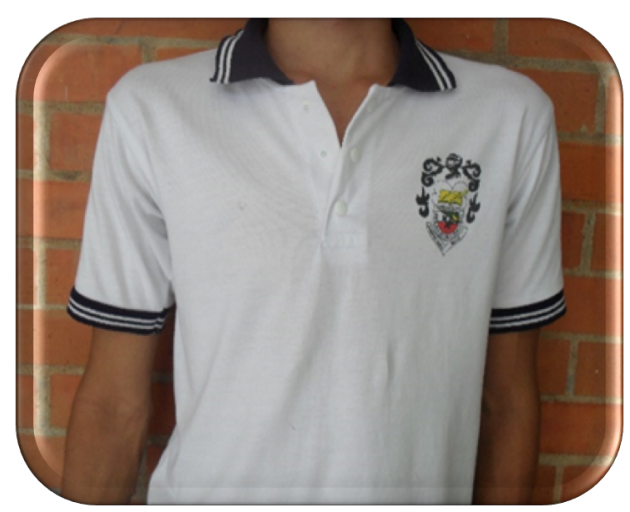

Uniforme tradicional con cuello

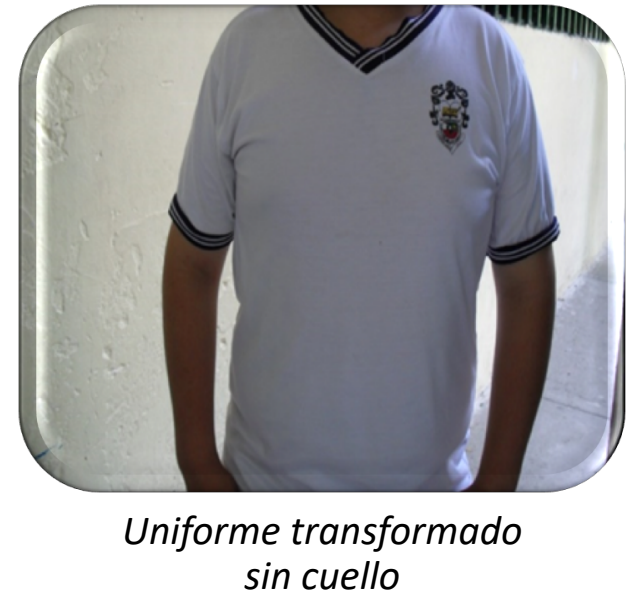

sin cuello

Los estudiantes que le cambiaron el cuello al uniforme introducen otro motivo para hacer cambios en la forma de vestir: el interés por verse atractivo a las mujeres; eso los hace sentir bien y aumentar su grupo de admiradoras, y sienten que con un toque de diferencia será más fácil conseguir pareja. Otro de los estudiantes entrevistados destaca que, además del deseo de cambiar su apariencia para ser diferentes, los jóvenes de hoy ya no están dispuestos a obedecer las disposiciones de los adultos por el solo hecho de la condición de su mayoría de edad con respecto a ellos:

Yo creo que, como te dije, soy uno de los pocos que buscan esa rebeldía; yo fui punkero, usé mi cresta, usé mis botas, pero yo me di cuenta que [sic] la idea no es la apariencia, sino las ideas. Hoy en día me di cuenta de eso y mira que he conseguido más felicidad, entonces yo creo que, para volver al tema, hay que reconocerle al estudiante, eso es lo que ha hecho que las instituciones cambien. Si el estudiante quiere algo busca la manera de lograrlo, el estudiante es sin miedo, el estudiante la sopa que no le gusta no se la toma, los profesores tienen que reconocer que para bien o para mal el estudiante cuando quiere algo, como sea lo consigue. En las instituciones educativas los estudiantes, aunque cueste aceptarlo, somos los que movemos todo, y cuando los estudiantes decidimos a luchar y a tumbar una ley hemos demostrado que los estudiantes somos capaces, sin importar nada. (Entrevista 5)

Este estudiante señala que la vinculación a grupos y la adopción de determinados estilos es una señal de rebeldía. En esto coincide con otros alumnos, que destacan que su forma de presentarse a los otros hace parte de un interés por diferenciarse del común de la gente. Acompaña este argumento con el de la gran 
capacidad que, según él, tienen los jóvenes para transformar y no aceptar aquello con lo que no están de acuerdo.

Las explicaciones que dan los estudiantes a la modificación de su uniforme evidencian la afirmación del sujeto sobre su cuerpo; con dichas transformaciones los estudiantes construyen estrategias de visibilización, diferenciación y distanciamiento. En estos casos la introducción de "algo novedoso" a la apariencia corporal expresa que los alumnos están haciendo una construcción de sí mismos (Cabra, 2010). La tensión por el uniforme devela la enorme creatividad que los jóvenes aplican para singularizar unas prendas dirigidas a la unicidad de cuerpos en el escenario educativo. Formar la subjetividad, en este sentido, significa desplegar la singularidad subjetiva, "abrir las vías para que los individuos se desarrollen desde sus propias coordenadas existenciales, desplegando sus capacidades a partir de una auto-referencia subjetiva, es decir, de la reflexión sobre su propia libertad" (Cubides, 2004.p113).

Los cambios en el uniforme constituyen la ruptura con el canon institucional que emerge de la desacralización del cuerpo y de los símbolos, a partir de representaciones divergentes a la institución. En este sentido, el desafío de la escuela es construir nuevas prácticas y representaciones culturales de pertenencia, por medio de dispositivos inclusivos que valoricen prácticas, símbolos y creencias juveniles como expresiones imprescindibles en la constitución de individuos autónomos y responsables (Falconi, 2004).

Los fragmentos de entrevistas dan indicios de la configuración de "sujetos corporizados" que hacen del reconocimiento de su singularidad el eje de la subjetividad (Yáñez, 2010); en la escuela, el cuerpo se torna en una muy buena opción para trazar referentes de existencia; más que un asunto ligero o frívolo, el cuerpo es un vector relevante para la configuración de la subjetividad. Las manifestaciones de singularidad que muestran los alumnos se entienden dentro de procesos de socialización escolar, los cuales conducen a una individualización creciente en la medida en que cada joven hace parte de campos sociales diferentes, pues las sociedades contemporáneas han sido atravesadas por una tendencia estructural a la singularización. Sin embargo, en esta investigación se estableció que en la escuela se presenta un fenómeno muy interesante: por un lado, los jóvenes estudiantes no paran de denunciar la arbitrariedad de decisiones que no traten de la misma manera a todo el mundo, pero, por el otro, exigen con mucha vehemencia el respeto a la personalidad de cada uno. Mientras se rechaza cualquier acción que cuestione la igualdad, la aplicación institucional de criterios de homogenización se considera abusiva (Martucelli, 2010).

Si bien a los alumnos les molesta que haya tratos preferentes en el colegio que lesionen el derecho a la igualdad, también les molesta que se cuestionen sus peculiaridades, para lo que usan dos argumentos: no querer parecerse a la mayoría, y la comodidad y el bienestar personal, como lo evidencian los fragmentos de entrevistas transcritas. 
La tensión entre identidad y diversidad planteada por los estudiantes es una de las mayores tensiones presentes en las sociedades contemporáneas, por los procesos de mundialización de la cultura que han exacerbado la búsqueda de referentes identitarios, en la que se combinan tanto la resistencia a procesos de uniformización, como la apropiación de variados modelos culturales que circulan en los medios de comunicación y en las diferentes interacciones que establecen los sujetos en sus prácticas sociales (Herrera, 2009).

En este estudio, en el que la defensa de la singularidad se considera una expresión que evidencia la construcción de subjetividad, se ha visto con claridad la necesidad de reconocer la singularización creciente de las trayectorias personales, es decir, el hecho de que los alumnos tienen acceso a experiencias diversas a través de las cuales se quieren singularizar, aun cuando ocupen posiciones sociales similares.

\section{Expresiones de autonomía}

La defensa de la autonomía personal fue la segunda expresión del primer grupo que evidenció la construcción de subjetividad política que se identificó en los estudiantes con los que se trabajó. Una de las formas a través de las cuales estos jóvenes muestran que han adquirido autonomía es su forma de actuar o de expresarse en la escuela. A continuación, se presenta el fragmento de una entrevista que en la que la que se puede sugerir que la autonomía se despliega en forma de definición de sí, y de significación y resignificación como sujeto político:

Cada tres o cuatro meses yo citaba a los representantes de grado y consejeros de bienestar para una reunión para hacer las preguntas sobre sus necesidades; yo preguntaba cuáles son las dificultades que ustedes ven en la institución, y decían bueno, que hay problemas de goteras, que esto está dañado, entonces mi papel es como de informarle a los directivos las necesidades, los arreglos; mandé una solicitud para el arreglo del salón de idiomas de $11^{\circ}$ de la mañana. Me han tenido mucho en cuenta para la solución de estos problemas, se han tapado goteras, se han pintado paredes. El gobierno escolar es muy importante porque les permite a los directivos conocer la perspectiva de los estudiantes; son muy importantes nuestras funciones tanto para los directivos como para los estudiantes, ya que se ve que hay unas personas que están representando a los estudiantes, que están valiendo [sic] sus derechos, están siendo personas, estamos trabajando a favor de ellos. (Entrevista 10, contralor estudiantil 11º)

Si bien el argumento de la ley aflora contantemente y mueve a los estudiantes a llevar a cabo algunas acciones jurídicas propiamente dichas, hay que decir también que normalmente tienen iniciativas y requerimientos por la vía del diálogo, los cuales se hacen a través de las instancias institucionales regulares, que consideran corrientes y naturales. Por tal razón, no entienden que no sean 
aceptadas y rechazan las negativas: seguidamente así, se presenta otro fragmento de la entrevista 2 sobre el caso del ingreso de un televisor a una institución educativa. La situación generó reclamación de derechos por las sanciones disciplinarias impuestas a los estudiantes:

En el caso del televisor la entrada fue que nosotros muy cordialmente le pedimos permiso al rector y nos dijo que no, sabiendo que todos ya estábamos afuera, pues la mayoría, todo el colegio estaba afuera y pues un partido de selecciones... ¿si me entiende?, a todo mundo le gustaría vérselo, entonces él nos dijo que no, entonces el compañero dijo que él mandaba por un televisor, entonces nosotros le dijimos que sí, nosotros fuimos por el televisor y un compañero lo entró, y nosotros abrimos el salón con un palo, nos metimos para allá y llamamos a todo el colegio, a todos los que cupieron, y los metimos allá; fueron unos profesores y nosotros cerramos la puerta y no nos dijeran nada, y unos estudiantes lo veían desde afuera, otros de adentro, cuando empezó perdiendo Colombia bueno, cuando el rector llegó y en esa hicieron un gol y el rector se paró frente al televisor, nadie le paró bolas, ni le hizo caso y él se fue, entonces nosotros seguimos viendo el partido. (Entrevista 2)

Pues no es justo, pues todo el mundo con ganas de verse el partido, y al ver que no dejaron pues a uno le da un poco de rabia, pues, no era ni mayor cosa, era solo poner un videobeam y poner a ver el partido; y es más, el rector dijo que no quería que se lo viera nadie, él dijo que no podía, él dijo que no quería que nadie se lo vea [sic], era solo un capricho de él. (Entrevista 3)

En este relato sobre el acontecimiento de la entrada de un televisor sin permiso para ver un partido de fútbol, los estudiantes dicen actuar por su cuenta por tres razones: porque sienten que como jóvenes tienen derecho a divertirse, porque sienten que no afecta a nadie - ni a su proceso de formación- ver el partido, pero, muy especialmente, porque dicen no estar dispuestos a aceptar la imposición y capricho del rector. Esto indica que cuando los jóvenes sienten que las razones de los adultos no son suficientes, son arbitrarias o son autoritarias, ellos sencillamente no las acatan y las ignoran, sin reparar en que incumplen las normas del establecimiento educativo.

Las opiniones y las acciones de los estudiantes de secundaria aquí expuestas sugieren un proceso de redefinición y de significación entre exigencias sociales, prácticas educativas y las condiciones que las instituciones educativas imponen (Alvarado y Ospina, 2007). Los procesos de subjetivación pasan por la recuperación de la autonomía, entendida como la capacidad de pensar por sí mismo, sin desconocer al otro, y reconocer, crear y disponer en la práctica los principios que orientan la vida. En este estudio entendemos la autonomía como la capacidad de pensar y de actuar con otros jóvenes y con los adultos desde sus propias posturas, en diversos escenarios de su cotidianidad.

Al respeto, en su entrevista un estudiante señaló: 
Entonces como para agregar ahí, como cuando, digámoslo, pongámosle un ejemplo familiar: cuando un padre evoluciona tiene..., hace una familia, hace una familia y tiene hijos, vemos como que el papá va quedando atrás en el tiempo porque va a ver algo nuevo, siempre va a ver nueva música, nuevos bailes, nuevas modas; entonces, el hijo va creciendo y va teniendo esas nuevas herencias, va heredando todo lo nuevo, mientras que el papá va quedando en lo antiguo, en lo que antes le parecía a él; no es que, bailar era chévere... no es que esto, y esto se queda en sus conocimientos; lo que él creía que era más lógico, pero entonces por eso, hace que el padre tiene que evolucionar con sus hijos, por eso es que a veces cuando, digamos, un papá, digamos, tienen un hijo de 15 años, el papá trata de cómo ser él, porque hay que evolucionar con los hijos, entonces eso es lo que sucede. Entonces yo creo que el estudiantado y la sociedad pues en general se cansan de ver como las mismas cosas, y se cansan de ver que ellos tienen ideas diferentes que no se les permite, entonces las generaciones van cambiando, exacto. Antes el voto a la mujer no se le permitía hasta que una persona con ideas locas llegó y dijo es que la mujer también tiene derechos y vamos a hacerlo así, cierto, entonces las cosas tienen que ir cambiando y se tienen que convertir; antes la religión católica era la única que gobernaba, pues gobierno absoluto, entonces las cosas... depende su cambio de tiempo o de años, tienen que cambiar porque las mismas personas también cambian y deciden que las cosas tienen que cambiar. (Entrevista 5)

Las palabras del estudiante resaltan la importancia del cambio, justifican las acciones de los jóvenes movidas por el deseo de dicho cambio, y subrayan la importancia de que los adultos, tanto en la familia como en el colegio, también cambien, "evolucionen". Esta transformación se plantea como una necesidad, como un deber hacer para convivir y comprender el mundo juvenil

A continuación, en la tabla 1 se presentan algunos datos en los que también se puede identificar expresiones de autonomía en los estudiantes.

Estos testimonios enviados a la coordinación de uno de los colegios de manera informal, en un papel o de manera verbal, son un ejemplo de las formas en que aflora la autonomía en los estudiantes. Las quejas expresan la preocupación de los estudiantes por la falta de condiciones adecuadas para su aprendizaje. La opinión generalizada es que la clase no se desarrolla normalmente por la indisciplina, el desorden, los gritos y el exceso de ruido atribuible a las deficiencias de los profesores para garantizar el orden.

Se considera novedoso que los estudiantes tomen la iniciativa de solicitar que se cree un ambiente que garantice su aprendizaje, lo que los desmarca de una opinión muy generalizada entre maestros, que ya había sido identificada en la investigación, según la cual los estudiantes no quieren estudiar; por el contrario, estos alumnos lo que exigen es que las autoridades escolares ejerzan sus funciones, y se encarguen de supervisar las aulas y garantizar los espacios de aprendizaje. Los reclamos de estos estudiantes los muestran no solo como poseedores de los derechos que la ley les ha reconocido, sino como sujetos 
activos que exigen ser protegidos y respetados como interlocutores que asumen tareas en la sociedad y pueden configurar sus vidas por sí mismos.

Tabla 1. Peticiones informales a la coordinación de la institución educativa

\begin{tabular}{|c|c|c|c|}
\hline $\begin{array}{l}\text { Grado del } \\
\text { estudiante }\end{array}$ & $\begin{array}{l}\text { Contra quién es } \\
\text { la queja }\end{array}$ & Recibe la queja & Contenido de la queja \\
\hline $8^{o}$ & Profesor & Coordinadora & $\begin{array}{l}\text { "Yo estaba parada al lado del escritorio del profe- } \\
\text { sor y él llamó a lista, y cuando llamó a un com- } \\
\text { pañero, él no escuchó por la bulla y le puso falta, } \\
\text { y yo le dije que estaba en la parte de atrás, y me } \\
\text { dijo que dejara de ser tan metida y me fuera a } \\
\text { sentar y estrujó a una compañera" (Queja de una } \\
\text { estudiante). }\end{array}$ \\
\hline $6^{\circ}$ & Estudiantes & Coordinadora & $\begin{array}{l}\text { "Señorita coordinadora, la presente es para infor- } \\
\text { marle que en el grado } 6^{\alpha} \text { no dejan dar clase y son } \\
\text { los mismos repitentes, a ver si usted puede hacer } \\
\text { algo o cambiarlos a otro salón, porque el profe- } \\
\text { sor no hace nada, él no hace respetar la clase" } \\
\text { (Queja de una estudiante). }\end{array}$ \\
\hline $6^{\circ}$ & Profesor & Coordinadora & $\begin{array}{l}\text { "Buenas tardes, coordinadoras, la presente es } \\
\text { para informarles que yo no entré a la clase del } \\
\text { profesor porque es que hacen mucho ruido y yo } \\
\text { no me aguanto ese fuerte ruido diario que me } \\
\text { toca con ese profesor, llego a mi casa a tomar } \\
\text { pastas. } \\
\text { Gracias por su atención" (Queja de una estu- } \\
\text { diante). }\end{array}$ \\
\hline $6^{\circ}$ & Estudiantes & Coordinadora & $\begin{array}{l}\text { "Se presentan las tres niñas y dicen estar muy } \\
\text { preocupadas por la indisciplina que se presenta } \\
\text { en la clase del profesor, además nos da pesar de } \\
\text { la forma como los compañeros tratan y le contes- } \\
\text { tan al profesor" (La coordinadora transcribe la } \\
\text { queja). }\end{array}$ \\
\hline $6^{\circ}$ & $\begin{array}{l}\text { Profesor } \\
\text { Estudiantes }\end{array}$ & Coordinadora & $\begin{array}{l}\text { "Se presenta un estudiante y manifiesta que las } \\
\text { clases del profesor son un desorden y permite } \\
\text { que los niños griten y griten, entonces él también } \\
\text { levanta la voz, y se forma más desorden a unos } \\
\text { nos duele la cabeza es imposible estar en estas } \\
\text { clases" (La coordinadora transcribe la queja). }\end{array}$ \\
\hline
\end{tabular}

Según Martínez y Cubides (2012), hay dos elementos muy importantes en la construcción de subjetividad política de los jóvenes estudiantes de secundaria: la capacidad y el evento. La primera es entendida como la fuerza de acción que se instala en el sujeto para activar, promover o posibilitar un aumento de su poder para disentir, movilizarse y provocar una alteración en la cotidianidad. Se habla de "alter-acciones", acciones que suceden tanto en el campo reflexivo como en el de la acción.

La inclusión de las dos expresiones anteriores - la defensa de la singularidad y las expresiones de autonomía- se lleva a cabo porque se entiende que la subjetividad de los estudiantes de secundaria se constituye con otros, pero se reconoce la posibilidad de sí sobre sí, es decir, un trabajo de ejercicio en la constitución de la propia subjetividad como un ejercicio ético de reconstruirse, pensarse, revaluarse y ubicarse en el lugar de la crítica, no solo como autoevaluación, sino como posibilidad de interrogar la verdad y lo que se les ha dicho que son.

Las peticiones de los estudiantes recuerdan la importancia de la vinculación de lo organizativo y lo pedagógico en los colegios. Para Sandoval (2000) la 
gestión pedagógica de los planteles es el enclave fundamental de los procesos de transformación; constituye el principal espacio que se debe transformar, incorporando desde aspectos políticos y estructurales, hasta la cultura colectiva de la escuela y su actuar cotidiano, que incluye lo administrativo, pedagógico y particular de los sujetos que en ella intervienen.

Esta es una perspectiva innovadora que reconoce el valor de las actividades que cada sujeto desarrolla en la escuela en su articulación a un fin común: mejorar la calidad de la educación que se imparte en cada escuela. La defensa de la singularidad y las expresiones de autonomía pueden entenderse también como la expresión de fenómenos como el que Ulrich Beck y Elizabeth Beck denominan individualización: la liberación de los roles tradicionales, desdibujarse de las clases sociales basadas en el estatus, los cambios en la estructura familiar, las condiciones de vida, las actividades de ocio y la distribución geográfica de las poblaciones: "La individualización es un concepto que describe una transformación estructural, sociológica, de las instituciones sociales y la relación del individuo con la sociedad" (Beck y Beck, 2003, p. 339).

Estos mismos autores sostienen que la lucha diaria por una vida propia se ha convertido en la experiencia colectiva de nuestras sociedades y que la ética de la realización personal es la corriente más poderosa de nuestros días. El ser humano que decide y configura, que aspira a ser el autor de su propia vida y el creador de una entidad individual, se ha convertido en el protagonista de nuestro tiempo. Mientras que antes la cultura se definía por las tradiciones, hoy debe hacerlo como un ámbito de libertad que protege a cada grupo de individuos, y tiene la capacidad de producir y defender su propia individualización.

\section{La interpelación del orden establecido}

\section{Percepción de desajuste o fractura del ejercicio del poder y las normas}

Otra de las expresiones que evidenció la construcción de subjetividades políticas en los estudiantes fue la percepción de desajuste en el ejercicio del poder y con las normas. Este desajuste se hizo evidente en dos manifestaciones: inconformidad con el ejercicio del poder y el sistema normativo, y un deseo explícito de modificaciones en estos dos aspectos. Los datos que se presentan a continuación así lo dejan ver:

Un estudiante presenta apelación a una sanción disciplinaria, con los argumentos de que no se respetó el debido proceso, se desconoció lo estipulado en el Manual de Convivencia del colegio, y él no tuvo una oportunidad real de defensa:

En el momento en que me presenté con mi acudiente el día viernes 7 de septiem-

bre, fui remitido a la Coordinación y de allí fui enviado al Comité Institucional 
de Convivencia Escolar. Me dijeron que dijera qué era lo que había pasado; yo les conté; entonces miraron el observador en el cual no había observación alguna en mi hoja de vida; los profesores dieron su opinión, el director de grupo dio referencias que yo era un buen estudiante, que no tenía anotaciones en el control, que tenía buenas calificaciones. En esta diligencia no se dejó presentar pruebas ni descargos, ni siquiera se preguntó si las tenía ni nada de eso. Esta audiencia como que fue un mero formalismo para legitimar después la sanción que me impusiera el rector. (Recurso de reposición y subsidio de apelación por falta disciplinaria, Institución II)

El estudiante cuestiona el procedimiento usado por la institución educativa para seguir el debido proceso, reconoce que tuvo derecho a expresarse sobre aquello que se le acusa, pero también recalca que el procedimiento es meramente retórico, ya que no se tiene realmente en cuenta lo que él dice ni sus pruebas a la hora de imponer la sanción por las faltas.

En el siguiente fragmento, un estudiante muestra su inconformidad ante la posibilidad de que los docentes y los directivos docentes castiguen a aquellos alumnos con dificultades académicas (pierden materias) o que han tenido comportamientos de indisciplina sacándolos de la selección de microfútbol hasta que mejoren:

No, yo estoy de acuerdo que [sic] los profesores, el rector, la coordinadora opinen sobre la selección; ellos nada tienen que ver, no dan una moneda, no dan un uniforme, no dan un minuto, con qué derecho vienen a opinar a quién meten y a quién sacan, quién juega y quién no juega. Por ejemplo, en este periodo las llevaba todas mal, perdí bastanticas, pero pues... pienso recuperarlas, para no tener muchos inconvenientes porque yo quiero ir a ese departamental; pero igualmente yo pienso, como le estaba diciendo, eso como es un departamental, no iría tanto el permiso del colegio sino con los padres porque nosotros vamos a representar al pueblo. (Entrevista 2)

El estudiante dice que debe haber restricciones al ámbito de opinión de las instituciones educativas. Según él, hay asuntos en los que el colegio no debe intervenir, ya que hace parte su vida personal, y aunque su rendimiento académico no sea el mejor, los docentes no tienen derecho a opinar sobre ello. Desde su punto de vista, nada tienen que decir de lo que pasa en el seleccionado deportivo quienes nada aportan a él.

Los testimonios evidencian que, en tanto acto de ruptura o fractura con lo instituido, la subjetivación implica un movimiento, un desplazamiento, una fuga respecto a la normalización y homogenización que objetiva el poder en la escuela. Algunos cambios introducidos por la legislación han influido en la formación de subjetividades políticas, porque se ha hecho efectiva la participación y el cuestionamiento de los estudiantes en la vida institucional con la creación y ampliación de la experiencia política. Así pues, la subjetivación de los estudiantes de secundaria juega un papel importante en la falta de identificación 
con el aparato normativo de la institución educativa; también cumplen un papel importante nociones como la igualdad, la reciprocidad y la justicia, y el valor social que los estudiantes le dan a la escuela y a la educación que en ella se imparte (Bonvillani, Palermo, Vázquez y Vommaro, 2008).

A continuación, se presentan otros documentos que inicialmente no habían sido contemplados como fuente de información dentro del diseño metodológico de la investigación. Sin embargo, al examinarlos con mayor detenimiento, se hizo evidente su valor para sustentar los argumentos sobre las expresiones que evidencian la configuración de subjetividad en los estudiantes. Este es un documento obligatorio en todas las instituciones educativas que cambia de denominación de una a otra: "observador", "anecdotario" o "agenda"; sirve, en principio, para registrar los actos, positivos y negativos, de cada uno de los estudiantes de un curso. Hoy en día es usado principalmente para registrar las faltas de los estudiantes que eventualmente pueden ser usadas en un proceso disciplinario. Lo que se presenta a continuación son algunas anotaciones tomadas de los observadores de estudiantes de distintos grados, en las que los estudiantes refutan al maestro que las escribe o se niegan a firmarlas.

Estos documentos son valiosos porque evidencian muchas de las transformaciones de la escuela secundaria actual, particularmente la emergencia de subjetividades políticas. De forma contraria a lo que pasaba décadas atrás, en las que el observador era visto con pánico en los colegios ${ }^{2}$, aquí ya no tiene ninguna función coercitiva; los alumnos no solo lo firman sin ningún problema, sino que, a su vez, lo utilizan para desafiar la autoridad del profesor, para mostrar su desacuerdo con él y hasta para burlarse de este (tabla 2).

Tabla 2. Anotaciones en el observador refutadas, comentadas o negadas a firmar por el alumno

\begin{tabular}{|l|l|l|}
\hline Grado & Observación & Comentario realizado a la anotación \\
\hline $11^{\circ}$ & $\begin{array}{l}\text { "El estudiante llega tarde a clases, } \\
\text { pide permiso después para ir al baño } \\
\text { y no se le permite porque acabaron } \\
\text { de entrar del descanso, más sin em- } \\
\text { bargo se sale sin permiso de clase de } \\
\text { cálculo". }\end{array}$ & $\begin{array}{l}\text { "No estoy de acuerdo porque es una nece- } \\
\text { sidad física". }\end{array}$ \\
\hline $11^{\circ}$ & $\begin{array}{l}\text { "La estudiante no entra a clase de } \\
\text { ética y a la dirección de grupo, no se } \\
\text { supo de ninguna justificación". }\end{array}$ & $\begin{array}{l}\text { "Pues la verdad a mín me dijeron que solo } \\
\text { era dirección de grupo y que era para de- } \\
\text { cir las materias que estábamos perdiendo } \\
\text { y pues yo ya sabía. En ningún momento } \\
\text { dijeron que usted iba a dar clases". }\end{array}$ \\
\hline
\end{tabular}

\footnotetext{
${ }^{2}$ El observador del alumno era conocido como el "libro negro", al que muchos estudiantes le temían; era usado en los colegios para registrar a quien cometía faltas. La conflictividad que ha emergido en la escuela hizo que fuera usado para evidenciar faltas disciplinarias de los alumnos, pero en algunas instituciones su uso se ha banalizado, ya no asusta a nadie y los maestros creen que diligenciarlo es un requisito que no sirve para nada, porque la legislación escolar favorece a los alumnos, sin importar las faltas que cometan.
} 


\begin{tabular}{|c|c|c|}
\hline Grado & Observación & Comentario realizado a la anotación \\
\hline $11^{\circ}$ & $\begin{array}{l}\text { "No colabora en clase, habla mucho, } \\
\text { se distrae con las companeras, no } \\
\text { atiende a las explicaciones, se le su- } \\
\text { giere un cambio de actitud frente a } \\
\text { las clases". }\end{array}$ & "No estoy de acuerdo". \\
\hline $6^{\circ}$ & $\begin{array}{l}\text { "No trabaja ni participa en clase de } \\
\text { sociales". }\end{array}$ & "No le firmo". \\
\hline $6^{0}$ & $\begin{array}{l}\text { "El estudiante no respeta las normas } \\
\text { de orden y cumplimiento del regla- } \\
\text { mento del Manual de Convivencia". }\end{array}$ & $\begin{array}{l}\text { "El profesor me apunta en el observador } \\
\text { porque yo no le hice caso, porque me } \\
\text { gritó y me dijo que no pasaba de sexto y } \\
\text { me insultó". }\end{array}$ \\
\hline $7^{\circ}$ & $\begin{array}{l}\text { "Le pegó un golpe en la cara a un } \\
\text { compañero y cuando el niño pone la } \\
\text { queja, utilizó palabras soeces y toma } \\
\text { una actitud muy negativa cuando se } \\
\text { le llama la atención. Se la pasó du- } \\
\text { rante la clase silbando y cuando se le } \\
\text { dijo que se le haría la observación } \\
\text { dijo dónde hay que firmarle". }\end{array}$ & $\begin{array}{l}\text { En el correctivo el estudiante escribió: "No } \\
\text { escribo nada y no le firmo". }\end{array}$ \\
\hline $6^{\circ}$ & $\begin{array}{l}\text { "Al alumno se le llama la atención } \\
\text { por desobedecer al profesor de in- } \\
\text { glés y tratarlo de viejo, el profe le } \\
\text { pregunta que si acabaron el trabajo y } \\
\text { dijo oigan a este". }\end{array}$ & $\begin{array}{l}\text { "Y se me enojó porque no dice, diga todo, } \\
\text { porque no dice que se me enojó y me } \\
\text { gritó". }\end{array}$ \\
\hline $6^{0}$ & $\begin{array}{l}\text { "El estudiante se levanta del puesto y } \\
\text { no participa en las actividades peda- } \\
\text { gógicas". }\end{array}$ & $\begin{array}{l}\text { "Lo que pasa es que uno no entiende la le- } \\
\text { tra del profesor". }\end{array}$ \\
\hline $6^{0}$ & $\begin{array}{l}\text { "Se le llama la atención al estudiante } \\
\text { por desobedecer al profesor y se } \\
\text { para demasiado del puesto". }\end{array}$ & $\begin{array}{l}\text { "Yo no agredí el profesor, solo le quité la } \\
\text { mano de encima mío porque me estaba es- } \\
\text { trujando". }\end{array}$ \\
\hline $6^{\circ}$ & $\begin{array}{l}\text { "El estudiante ingresó tarde a cla- } \\
\text { ses". }\end{array}$ & $\begin{array}{l}\text { "No, eso no fue así, me fui al baño y el } \\
\text { profesor me anotó y yo le dije que me } \\
\text { anotó por nada". }\end{array}$ \\
\hline $6^{9}$ & $\begin{array}{l}\text { "El estudiante crea indisciplina, } \\
\text { charla demasiado y trabajo poco". }\end{array}$ & $\begin{array}{l}\text { "Yo estaba esperando que una compañera } \\
\text { terminara el cuento y le estaba parando } \\
\text { bolas a un compañero que me pidió un fa- } \\
\text { vor y por eso me anotaron, pero eso no es } \\
\text { así". }\end{array}$ \\
\hline $6^{0}$ & $\begin{array}{l}\text { "Pronuncia palabras groseras en el } \\
\text { salón de clases". }\end{array}$ & "Falso". \\
\hline $7^{\circ}$ & $\begin{array}{l}\text { "No realizó actividades, estaba ju- } \\
\text { gando con un celular, hace dibujo en } \\
\text { el cuaderno de un compañero". }\end{array}$ & "Mentira". \\
\hline $7^{\circ}$ & $\begin{array}{l}\text { "Hace indisciplina en clase de mate- } \\
\text { máticas, tirándole pedazos de borra- } \\
\text { dores". }\end{array}$ & $\begin{array}{l}\text { "Yo no tiré borradores, el profesor se equi- } \\
\text { vocó". }\end{array}$ \\
\hline $7^{\circ}$ & $\begin{array}{l}\text { "Se presenta la acudiente para dialo- } \\
\text { gar sobre el desempeño de su hijo, } \\
\text { tiene bajo rendimiento en varias ma- } \\
\text { terias". }\end{array}$ & "No quiero firmar porque es injusto". \\
\hline $7^{\circ}$ & $\begin{array}{l}\text { "La niña se dirige a sus compañeros } \\
\text { con malas palabras dice 'la mari- } \\
\text { cada, sapo'. Lo anterior en clase de } \\
\text { castellano". }\end{array}$ & $\begin{array}{l}\text { "El profesor se equivoca yo no dije sapo. } \\
\text { Ok". }\end{array}$ \\
\hline
\end{tabular}




\begin{tabular}{|c|c|c|}
\hline Grado & Observación & Comentario realizado a la anotación \\
\hline $7^{0}$ & $\begin{array}{l}\text { "La joven llega a clases con una } \\
\text { bolsa llena de mangos que le pasa a } \\
\text { otra compañera para que se la } \\
\text { guarde. Se hace en la parte de atrás, } \\
\text { cuando el profesor pide la tarea no } \\
\text { entrega el cuaderno, afirmando que } \\
\text { se le olvidó, si trajo el de la compa- } \\
\text { nera que ella lo tenía". }\end{array}$ & $\begin{array}{l}\text { "Jajajaja sabiendo que ella me lo entregó } \\
\text { en la clase y yo en ningún momento me lo } \\
\text { llevé para mi casa. Ok y yo no me estaba } \\
\text { comiendo el mango ni mucho menos". }\end{array}$ \\
\hline $7^{\circ}$ & $\begin{array}{l}\text { "El estudiante no trabaja en clase de } \\
\text { español, fomenta la indisciplina". }\end{array}$ & "No le firmo". \\
\hline $7^{\circ}$ & $\begin{array}{l}\text { "El joven no trae implementos de tra- } \\
\text { bajo para la casa, se le pide el favor } \\
\text { que copie en una hoja y dice qué pe- } \\
\text { reza, también se le descubrió escul- } \\
\text { cando los libros de la docente en el } \\
\text { escritorio". }\end{array}$ & $\begin{array}{l}\text { "mmmmmmmm } \\
\text { mmmmmmmm } \\
\text { mmmmmmmm". }\end{array}$ \\
\hline $6^{o}$ & $\begin{array}{l}\text { "La estudiante golpeó en la cara a un } \\
\text { compañero, se agredieron mutua- } \\
\text { mente, no realiza el trabajo en clase, } \\
\text { reclama por las actitudes de su com- } \\
\text { pañero hacia ella, le dice bobo al } \\
\text { profesor". }\end{array}$ & "Eso es mentira". \\
\hline $8^{\circ}$ & $\begin{array}{l}\text { "La estudiante se acuesta en el piso } \\
\text { del salón con un compañero a escu- } \\
\text { char música en el aula en clase de } \\
\text { biología". }\end{array}$ & "No firmo". \\
\hline $8^{\circ}$ & $\begin{array}{l}\text { "La niña fue sorprendida tirando el } \\
\text { maletín de otro compañero al piso". }\end{array}$ & "Porque me lo tiraron en la cabeza". \\
\hline
\end{tabular}

Las observaciones registradas contienen llamados de atención de los docentes sobre impuntualidad, asistencia a clases, no realización de actividades, falta de respeto por las normas institucionales, interrupción del normal desarrollo de las clases, utilización de palabras soeces y agresiones físicas a los compañeros. La novedad en el observador y lo que es útil para este artículo son las anotaciones que hacen los estudiantes y con las cuales le responden al maestro; algunos dicen que no están de acuerdo, otros dan su versión de los hechos narrados en la observación o justifican sus acciones; dicen que el profesor miente o que la observación es injusta. Otros se niegan a firmar para mostrar su desacuerdo, e incluso uno de los estudiantes se burla de lo que escribió el profesor. Aunque el observador tiene un espacio para registrar los castigos a los estudiantes, este en la mayoría de las anotaciones está vacío, solo en algunas dice "llamado de atención". 
La lectura de las anotaciones evidencia que el observador es un inventario de las acciones y las actitudes que los docentes consideran faltas disciplinarias; algunas son descritas con mucho detalle y otras de una manera tan somera que ni siquiera queda claro cuál fue el comportamiento sobre el que se llamó la atención. El punto que se quiere destacar es el de los correctivos, porque siendo "una anotación en el observador" un mecanismo utilizado para imponer la disciplina a los estudiantes y, por tanto, mejorar su comportamiento, el espacio destinado a los correctivos no es el más importante dentro del documento; el esfuerzo de los docentes se centra en describir la falta-dejar su evidencia-, pero no se encuentran indicios de que ante un mal comportamiento se imponga al estudiante una acción pedagógica que lo lleve a reflexionar sobre su falta, a reconocerla como tal y a evitar repetirla en el futuro. De hecho, un estudiante puede tener diversas anotaciones por la misma falta sin que aparezcan las sanciones correctivas.

Estudios como los de Duschatzky y Corea (2002) enfatizan en que asistimos a un proceso de transformación en las representaciones y prácticas de la cultura estudiantil, debido a un declive de la eficacia simbólica de la escuela para hacer incorporar la norma y, por lo tanto, convocar las subjetividades de los jóvenes. Presenciamos un proceso de desinstitucionalización con variantes que dependen de la organización de la institución educativa y de la calidad de educación que se imparte, pero que en todos los casos influye en la experiencia escolar. Hay una batalla y un cuestionamiento a ciertos significados y procedimientos del dispositivo escolar, que impone un único modo de actuar y de pensarse como sujeto escolarizado. Por lo anterior, además de leer las demandas juveniles como un pedido de autoridad adulta, debemos leerlas como un requerimiento de la construcción normativa negociada, provisional y sujeta a cambios (Falconi, 2004). Lo que sucede en la escuela es la reafirmación de expresiones de libertad que están empezando a hacerse realidad en la vida cotidiana y, así, están cuestionando las bases mismas de nuestra coexistencia anterior.

\section{Reflexividad crítica al orden imperante}

La cuarta y última expresión de configuración de subjetividad identificada fue la reflexividad crítica al orden imperante; aquí se ubicaron aquellos discursos y prácticas en los que los estudiantes critican el orden escolar y hacen proposiciones.

El siguiente es un documento cuyo contenido fue muy diciente para la investigación. Se trata de la solicitud de una estudiante al rector para que le haga un llamado de atención a una docente por sus reiteradas faltas a las señales de tránsito en la parte externa del colegio: 
El día viernes 22 de febrero del 2013, se presentó un inconveniente con una docente de la institución propietaria del vehículo con placas ITR 936, que en reiteradas ocasiones ha irrespetado a la autoridad de los patrulleros en la vía, con infracciones como:

- Pasarse de la línea del pare.

- No avanzar cuando se le cede la vía

- Estacionarse en zonas de alto flujo vehicular.

Además, desciende del auto a discutir en tono agresivo, estos actos ameritan un llamado de atención y concientización a la docente. (Firma de la estudiante)

El texto permite inferir que la estudiante reprueba que la docente utilice su condición para no cumplir la ley como cualquier otro ciudadano, y para irrespetar a la policía. Considera que, si bien los hechos suceden fuera del establecimiento educativo, el comportamiento de la docente transmite un mal ejemplo, por lo tanto, convoca al rector a que como autoridad haga ver a la docente sus errores. La estudiante ha interiorizado como principio que todos debemos cumplir las normas y que la condición de docente debe servir para dar ejemplo, no para pasar por alto la normatividad y la autoridad.

En el fragmento que se presenta a continuación, el estudiante argumenta con la idea de que hay que ponerles un límite a los abusos del maestro- su denuncia en contra del profesor ante la Secretaría de Educación por maltrato, ya que, de no hacerlo, este continuará con sus agresiones físicas:

Yo me quejé porque yo no podía dejar así, que ese señor me siga pegando, además una compañera me dijo usted es que es bobo, vaya y ponga la denuncia, porque si eso es la segunda vez, mi mamá dijo que, si eso volvía a suceder, no responde, que mi mamá dijo que él no sabe lo que ella era capaz de hacer, si les pegan a sus hijos. (Entrevista 1)

A continuación, se trascribe un fragmento de entrevista en el que se pone en tela de juicio el procedimiento utilizado para sancionar a un estudiante:

Para definirnos la sanción, primero se encerraron a hablar un rato y después nos entraron a uno por uno, no nos dejaron entrar a los tres juntos; entonces en esas un compañero se paró así en la puerta a escuchar y yo no sé lo que le dijo, yo no sé lo que estaba diciendo el señor rector, que él era marihuanero, yo no sé, y entonces ese chino se entró y de allá lo tuvieron que sacar y lloraba de la rabia, pero él decía que ese señor es un mentiroso, que así no son las cosas y él salió y después entro él a hablar con el señor rector, con todos en el Consejo Directivo, y él le volvía y le recalcaba lo mismo, que así no era como él decía las cosas. (Entrevista 3)

Completa este grupo de datos la foto del cartel pegado en la puerta de uno de los salones de clase (ver imagen 3); ante la prohibición de entrar a la sala de profesores sin ser autorizados, un grupo de estudiantes escribe y pega en la 
puerta del salón un cartel donde también se prohíbe la entrada de profesores y directivos.

Imagen 3. Cartel pegado en la puerta de uno de los salones de clase Foto de la autora

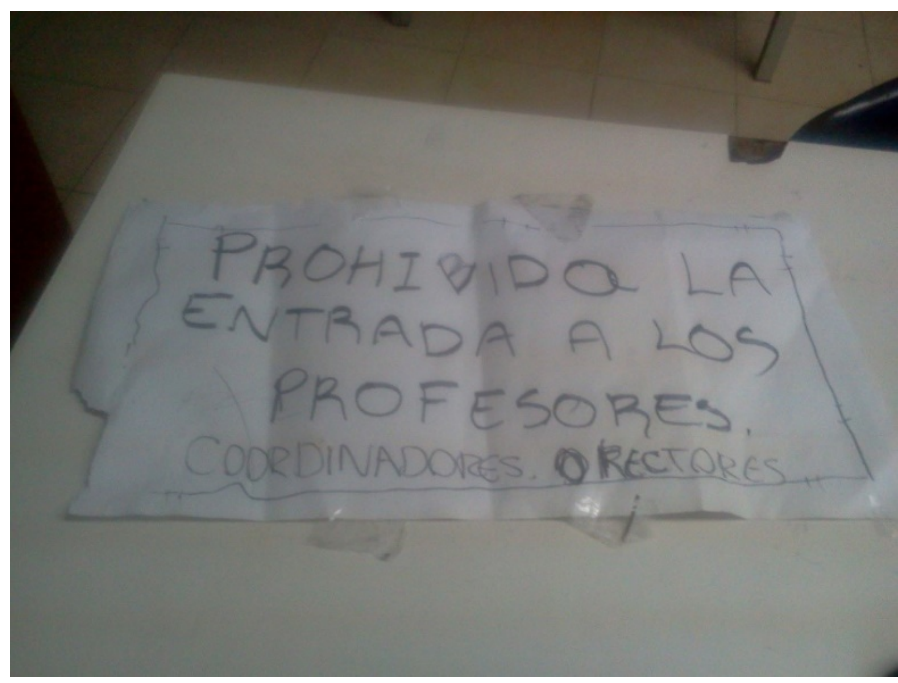

Según los estudiantes, así como los profesores restringen la entrada a su sala, los estudiantes también pueden hacer restricciones a la entrada a su salón de clases. Para los estudiantes la falta de consecuencia entre el discurso y el hacer de los docentes se ha instalado en la escuela, por lo que exigen condiciones de igualdad y de equidad. A los ojos de los estudiantes, las normas marcan pautas, pero quienes las transgreden son quienes tienen que hacerlas cumplir; así, "las normas no producen efectos prácticos ni construyen el límite desde lo simbólico, es la norma que, a partir de instituir un principio de ilegalidad basado en la formulación de la igualdad, habilita la construcción de un semejante" (Rotondi, 2011, p. 50).

Se dejó para el final un grupo de documentos de distinta naturaleza que comparten una crítica y un llamado a la renovación de la esencia misma de la escuela, de su componente pedagógico y de su forma de enseñar.

El primer texto es un artículo de uno de los estudiantes publicado en el periódico estudiantil de una de las instituciones en el 2013. El estudiante dice que su aporte es una crítica constructiva respecto a lo que son las clases aburridas

Crítica: las llamadas clases malucas

Muchas veces al hacer reflexiones nos piden que como estudiantes seamos honestos, que expresemos lo que sentimos y que en vez de ser criticones aportemos con críticas constructivas, por esto mi reflexión hoy es: 
Hay algunas clases muy agradables, podríamos llamarlas "buenas" despiertan el interés por su contenido o por la actitud que asume el profesor frente a ellas, pero también hay otras que podríamos denominar "malucas", empezando por aquellas que son monótonas y siempre comienzan con un tono de voz un poco llamativo, una explicación rara y un taller largo, muy, muy largo que ni siquiera alcanzamos a terminar, también se identifican por un ambiente que te hace dar sueño, te hace estar aburrido, no te provoca hacer nada, las horas te parecen eternas, te dan muchas ganas de salir rápido, uno se estresa mucho. No te dan ganas de mover ni los brazos y finalmente escuchas el timbre sonar.

Respetuosamente considero que todo podría mejorar, si todos contribuimos en poner más ánimo, más interacción con los estudiantes, hay que ponerles goce a las cosas, más diversión. Los estudiantes también debemos aportar con responsabilidad, con la convicción de que la educación es la única que puede liberar al hombre de la esclavitud que genera la ignorancia. (Estudiante del grado $9^{\circ}$ )

Si bien el estudiante cierra el artículo diciendo que hay responsabilidad de los estudiantes en la creación de un buen ambiente de aprendizaje, el mensaje va dirigido especialmente a los maestros, los llama a reflexionar sobre qué tipo de clase están orientando, si "la maluca o la agradable". Es sin duda un llamado a la implementación de metodologías que sean más atractivas y agradables para los estudiantes.

A continuación, se transcribe una solicitud de cambio de docente con el argumento de falta de competencia en la acción pedagógica. La solicitud tiene dos documentos:

\section{Documento 1}

La presente es para dirigirle a usted la propuesta del cambio del profesor de matemáticas del grado $8^{\circ} \mathrm{C}$, puesto que se han generado muchas dificultades con el modo de enseñanza del profesor.

Los alumnos de $8^{\circ} \mathrm{C}$ nos hemos quejado con las coordinadoras, porque no entendemos ni nos parece adecuado el modo en que nos enseña, sus explicaciones no son claras y no da ni los logros del periodo como guía de enseñanza. Aclarando que matemáticas es una de las áreas más importantes, por lo tanto, se necesita un buen docente.

Con el fin de lograr una mejor educación para todos los estudiantes y agradeciendo su atención, esperamos pronta respuesta.

POSDATA: Sabemos el esfuerzo que el docente hace para enseñarnos, pero es necesario que nos lo cambie por nuestra educación y buen entendimiento.

NOTA: Aparece en manuscrito una anotación del rector sobre preguntas que les formuló a los estudiantes a la hora de entregar la carta. La anotación dice:

Manifiestan que el docente deja hacer lo que quieren en clase, que es gritón, habla por celular. No trae las clases preparadas. (Firman 22 estudiantes del grado $8^{\circ} \mathrm{C}$ ) 
Ante la falta de respuesta a la petición anterior, los estudiantes del grado $8^{\circ} \mathrm{C}$ se dirigen nuevamente al rector, expresando lo siguiente:

Documento 2

La presente es para informarle que los estudiantes del grado $8^{\circ} \mathrm{C}$ estamos asistiendo cumplidamente a las clases del profesor del área de matemáticas, lo cual no quiere decir que estemos entendiendo; asistimos por respeto tanto al profesor como a la institución.

Aceptamos que el comportamiento de algunos compañeros no es adecuado, pero necesitamos una pronta respuesta de su parte, o si no procederemos a no entrar más a esta clase, puesto que no estamos recibiendo una educación adecuada.

Esperamos que el día viernes 14 de febrero ya esté solucionado este tema.

Mientras tanto Yo: como estudiante, me comprometo con usted a colaborar con mis compañeros para que asistan a clases.

No le aseguro que entendemos, pero cumpliremos asistiendo y teniendo un buen comportamiento, así mismo, esperamos nos resuelva el problema.

En la parte de atrás de la carta puede ver la asistencia, y hasta el día viernes la recogeré cumplidamente y la haré firmar como puede ver del docente y de la representante del grado $8^{\circ}$.

Gracias por su atención, esperamos pronta respuesta. (Firman 33 de los estudiantes que asistieron a la clase de matemáticas del día 10 de febrero y la del docente)

Este grupo de estudiantes decide no entrar más a una de las clases porque consideran que el docente no sabe enseñar, pero que además no tiene interés de aprender puesto que no prepara las clases. A esto le agregan unos comportamientos que consideran inadecuados, como el mal genio. Ante la falta de respuesta a la primera petición, el grupo hace llegar una segunda en la que fijan un plazo al rector para que les solucione el problema. Expresan que están asistiendo a clase por "cortesía", pero que son muy conscientes de que no están aprendiendo nada, pues conocen la forma de dictar las clases de otros docentes que sí enseñan bien.

Teniendo en cuenta argumentos como los de Byung-Chul (2013 y 2014) según los cuales parte de la socialización que ocurre en la escuela está mediada por los discursos y prácticas de disciplinamiento de tiempos y espacios y que vivimos en una época de psicopolítica digital, donde el poder interviene en los procesos psicológicos inconscientes. El psicopoder es más eficiente que el biopoder, por cuanto vigila, controla y mueve a los hombres no desde fuera, sino desde dentro. Es importante subrayar que el artículo no pretende plantear que en las instituciones en las cuales se hizo la investigación no existan expresiones de arbitrariedad de las autoridades escolares, que se caractericen por relaciones 
horizontales entre los profesores y los estudiantes, o que estén libres de discursos y prácticas orientadas al disciplinamiento del alumnado.

Lo que se ha querido es reflexionar, teorizar y hacer evidentes la emergencia de discursos y prácticas de estudiantes que paulatinamente han provocado cambios en la organización escolar, en las relaciones entre sus actores y normatividad orientada a regular dichas relaciones teniendo como telón de fondo el concepto de subjetividad política. Sin que esto signifique que no contemplemos las limitaciones de dicho concepto porque como señala Kriger (2011), no toda reivindicación de derecho es una acción política. Desde su punto de vista, solo hay práctica política cuando el sujeto que interpela está consciente de su actividad transformadora del orden establecido.

\section{Conclusiones}

Cuatro fueron las expresiones de subjetividad política que se evidenciaron en los discursos y prácticas de reivindicación de derechos de los estudiantes dentro de dos grupos: el primero es el de las narraciones de construcción de sí, integrado por expresiones en las que se defiende la singularidad y se manifiestan algunas expresiones de autonomía. En el segundo se interpela el orden establecido, pertenecen a él hechos en los que los estudiantes tienen la percepción de que hay desajustes entre las normas y el ejercicio del poder; también pertenecen a este grupo ciertos discursos y prácticas en los que los estudiantes muestran que tienen reflexividad crítica frente al orden imperante. Todas estas expresiones permiten comprender mejor las reivindicaciones de los jóvenes estudiantes que pugnan por el reconocimiento político y por la inclusión de sus expectativas dentro de una relectura de la ciudadanía.

\section{La defensa de la singularidad}

La defensa de lo singular estuvo marcada por la protección a un estilo personal, por una forma de presentar el cuerpo, de arreglarlo, embellecerlo e incluso transformarlo, todo bajo la justificación de querer ser único. La lectura de las manifestaciones de los alumnos implica una comprensión del cuerpo en su complejidad, como soma, constante biológica y constructo cultural. La continua aparición de la defensa de un estilo personal, ligada siempre a la forma de presentar el cuerpo, se enmarca en los cambios sociales y culturales contemporáneos, que han generado modificaciones en el estilo de vida y en las prácticas de cada grupo generacional 


\section{Expresiones de autonomía}

La defensa de la autonomía personal fue el segundo grupo de expresiones que evidenció la construcción de subjetividad que se identificó en los estudiantes con los que se trabajó. Una de las formas a través de las cuales estos jóvenes muestran que han adquirido autonomía es su forma de actuar o de expresarse en la escuela.

Las opiniones y las acciones de los estudiantes expuestos permiten inferir un proceso de redefinición y significación entre las exigencias sociales, las prácticas educativas y las condiciones que las instituciones educativas imponen. Los procesos de subjetivación pasan por la recuperación de la autonomía, entendida como la capacidad de pensar por sí mismo sin desconocer al otro, y reconocer, crear y disponer en la práctica los principios que orientan la vida.

Los discursos de los estudiantes resaltan la importancia del cambio, justifican las acciones de los jóvenes movidos por el deseo de dicho cambio, y subrayan la importancia de que los adultos, tanto en la familia como en el colegio, también cambien de mentalidad; este cambio se plantea como una necesidad, como un deber hacer para convivir y comprender el mundo de los estudiantes. El contenido y el tono de algunas peticiones que hacen los estudiantes -en el marco de una acción judicial como la tutela o un derecho de petición o en una nota informal, una queja para que mejore el colegio- dejan vislumbrar cómo afloran expresiones de autonomía.

\section{Percepción de desajuste o fractura del ejercicio del poder y las normas}

Además de la defensa de la singularidad y de las expresiones de autonomía, otra expresión identificada en la construcción de subjetividades políticas en los estudiantes fue la percepción de desajuste entre el ejercicio del poder y las normas. Este desajuste se hizo evidente en dos manifestaciones: inconformidad con el ejercicio del poder y el sistema normativo, y un deseo explícito de modificaciones en estos dos aspectos.

\section{Reflexividad crítica al orden imperante}

La cuarta expresión de configuración de subjetividad que se identificó es la reflexividad crítica al orden imperante; aquí se ubicaron aquellos discursos y prácticas en los que los estudiantes critican el orden escolar y hacen proposiciones. Dicha reflexividad es leída como acción política porque implica cuestionamientos al ejercicio del poder de las autoridades escolares sobre los jóvenes.

Los estudiantes evidencian configuración de subjetividad política cuando muestran voluntad de actuar y de ser reconocidos cuando oponen a la lógica 
institucional de su colegio la lógica de su propia producción, cuando sus actos y discursos demuestran el deseo de crear una historia personal, cuando actúan sobre sí mismos para construir su experiencia y en dicha experiencia adquieren la capacidad de cuestionar su cotidianidad. Los datos recogidos permitieron ver la emergencia de procesos de subjetivación cuando los estudiantes demostraron la conciencia que tienen del mundo y de sí mismos, con sentimientos de libertad que hacen que tomen distancia del orden natural establecido, con capacidad de convicción, crítica y autonomía. Los procesos de subjetivación o de construcción de subjetividad política de los escolares son una instancia de resignificación y de apropiación material y simbólica que se produce en espacios de socialización; por tal razón, en este estudio la comprensión de la producción de subjetividad de los estudiantes de secundaria implicó involucrar por lo menos algunos aspectos de su historia personal y de sus interacciones con el contexto.

\section{Bibliografía}

Alvarado, S. y Ospina, H. (2007). Las concepciones de equidad y justicia en niños y niñas: desafíos en los procesos de configuración de la subjetividad política. En E., Vasco. S., Alvarado, C., Echavarría y P., Botero. (Eds.). Justicia, moral y subjetividad política en niños, niñas y jóvenes. Manizales Colombia: CINDE.

Alvarado, S., Ospina, H., Botero, P. y Muñoz, G. (2008). Las tramas de la subjetividad política y los desafíos a la formación ciudadana en jóvenes. Revista Argentina de Sociología, 6(11), 19-43.

Alvarado, S. Botero, P. y Ospina, H. (2010). Subjetividades políticas: sus emergencias, tramas y opacidades en el marco de la acción política. Mapeo de 61 experiencias con vinculación de jóvenes en Colombia. Revista Internacional de Filosofía Iberoamericana y Teoría Social Utopía y Praxis Latinoamericana, 15 (50), 39 - 55.

Alvarado, S. Patiño, J. Ospina, M. (2012). Reflexiones sobre la construcción social del sujeto joven vinculado a experiencias de acción política en Colombia: acontecimientos, movilizaciones, poderes. En: C., Piedrahita. A., Díaz y P., Vommaro, (Comp.). Subjetividades politicas: desafíos y debates latinoamericanos. Bogotá: Instituto para la Investigación Educativa y el Desarrollo Pedagógico - IDEP. CLACSO - Consejo Latinoamericano de Ciencias Sociales.

Beck, Ulrich y Beck, E. (2003). La individualización. El individualismo institucionalizado y sus consecuencias sociales y políticas. Barcelona: Paidós.

Benjamin, W. (1992). Capitalismo como Religión. En Gesammelte Schriften, tomo IV, Frankfurt del Meno.

Bombillani, A., Palermo, A., Vázquez, M. y Vommaro, P. (2008). Juventud y política en la Argentina (1968-2008). Hacia la construcción de un estado del arte. Revista Argentina de Sociología, 6 (11), 44-73.

Byung-Chul, H. (2013). La sociedad de la transparencia. Barcelona: Herder Editorial, Byung-Chul, H. (2014). Psicopolítica: Neoliberalismo y nuevas técnicas de poder, Barcelona: Herder Editorial. 
Cabra, N. (2010). Video juegos: Máquinas del tiempo y mutaciones de la subjetividad. Revista Signo y pensamiento, 57, 162-177.

Cubides, H. (2004). Formación del sujeto político. Escuela medios y nuevas tecnologías de la comunicación y la información. En M., Laverde. G., Daza y M., Zuleta, (eds.). Debates sobre el sujeto. Perspectivas contemporáneas. Bogotá: Universidad Central - Siglo del hombre Editores.

Deleuze, G. (1990). Post-scriptum sobre las sociedades de control, en G. Deleuze, Conversaciones. (pp. 277-286). Valencia: Pre-Textos.

Departamento Nacional de Estadísticas DANE. (2016). Estratificación socioeconómica para servicios domiciliarios. Bogotá.

Díaz, B. (2002). El cuerpo en boca de los adolescentes. Grupo interdisciplinario de investigadores en Cultura Somática de la Universidad de Antioquia. Medellín: Instituto Colombiano para el Desarrollo de la Ciencia y la Tecnología Francisco José de Caldas.

Domínguez, M. (2008). Integración social de la juventud cubana hoy. Una mirada a su subjetividad Revista Argentina de Sociología, 6, (11), 74 - 95.

Dubet, F. (2010). Sociología de la experiencia. Madrid: Editorial Universidad Complutense de Madrid.

Dubet, F. (2011). La experiencia sociológica. Barcelona: Editorial Gedisa.

Duschatzky, S. y Corea, C. (2002). Chicos en banda. Los caminos de la subjetividad en el declive de las instituciones. Buenos Aires: Ediciones Paidós.

Falconi, O. (2004). Las silenciadas batallas juveniles: ¿Quién está marcando el rumbo de la escuela media hoy? KAIROS Revista de temas sociales, 14, 1-10.

González, F. (2012). La subjetividad y su significación para el estudio de los procesos políticos: sujeto, sociedad y política. En: C., Piedrahita. A., Díaz y P., Vommaro, (Comp.). Subjetividades politicas: desafíos y debates latinoamericanos. Bogotá: Instituto para la Investigación Educativa y el Desarrollo Pedagógico - IDEP. CLACSO Consejo Latinoamericano de Ciencias Sociales.

Guattari, F. (1998). El nuevo paradigma estético. En D. Fried Schmitman (coord.), Nuevos paradigmas, cultura y subjetividad (pp. 85-204). Madrid: Paidós.

Herrera, M. (2009). Ciudadanía y escenarios para su formación y aprendizaje: Las vicisitudes del sujeto político. En: C., Vasco. E., Vasco y H., Héctor (Eds.). Ética, política y ciudadanía. Manizales. Siglo del Hombre Editores. Universidad de Manizales. Fundación Centro Internacional de Educación y Desarrollo Humano. CINDE.

Imaz, C. (2011). Descongelando al sujeto. Subjetividad, narrativa e interacciones sociales contextualizadas. Revista Acta Sociológica, 56, 37 - 57.

Kriger, M. (2011). La enseñanza de la historia reciente como herramienta clave para la formación del pensamiento político. Avances de una investigación en curso sobre jóvenes estudiantes argentinos. Ponencia para el Congreso Interescuelas. Buenos aires.

Martínez, M. y Cubides, J. (2012). Acercamientos al uso de la categoría de' subjetividad política' en procesos investigativos. En: C., Piedrahita. A., Díaz y P., Vommaro, (Comp.). Subjetividades políticas: desafíos y debates latinoamericanos. Bogotá: Instituto para la Investigación Educativa y el Desarrollo Pedagógico - IDEP. CLACSO Consejo Latinoamericano de Ciencias Sociales.

Martuccelli, D. (2010). La individuación como macrosociología de la sociedad singularizada. Revista Persona y sociedad, 24, (3), 9-29. 
Palacios, N. y Herrera, J. (2013). Subjetividad, socialización política y derechos en la escuela. Magis, Revista Internacional de Investigación en Educación, 5 (11), 413-437.

Palacios. N. (2017). prácticas políticas en la escuela. un estudio en tres instituciones educativas de secundaria en Colombia. Revista Última Década, 46, 213-257

Rotondi, G. (2011). Democratización y ciudadanía en centros de estudiantes secundarios. Córdoba: Escuela de Trabajo Social y Centro de Estudios Avanzados, Universidad Nacional de Córdoba.

Sousa-Santos, B. de (1998). De la mano de Alicia. Lo social y lo político en la postmodernidad. Bogotá: Siglo del Hombre Editores y Ediciones Universidad de los andes.

Sandoval, E. (2000). La trama de la escuela secundaria: institución, relaciones y saberes. México D.F.: Plaza y Valdés/Universidad Pedagógica Nacional.

Sabucedo, J. M. (1996). Psicología política. Madrid: Síntesis Psicológica.

Tenti-Fanfani, E. (2008). Mirar la escuela desde afuera. En E. Tenti-Fanfani (coord.), Nuevos temas en la agenda de política educativa (pp. 11-26). Buenos Aires: iipeUnesco/ Siglo xxi Editores.

Urresti, M. (2008) Nuevos procesos culturales, subjetividades adolescentes emergentes y experiencia escolar. En: E. Tenti-Fanfani, (Comp.). Nuevos temas en la agenda de política educativa. Coordinador Emilio. Buenos Aires: IIPE. UNESCO. Siglo XXI Editores.

Yáñez, C. (2010). Viaje al uno en la multiplicidad. La identidad personal y sus sí mismos. Bogotá: Universidad Nacional de Colombia.

\section{Nota biográfica}

NANCY PALACIOS MENA es licenciada en Ciencias Sociales, Magister en Sociología, Doctora y Posdoctora en Ciencias Sociales Niñez y Juventud. Es profesora de la Facultad de Educación de la Universidad de los Andes. Sus líneas de investigación son la sociología de la educación, didácticas de las ciencias sociales y etnoeducación. Orcid: http://orcid.org/0000-0003-1318-0728

Recibido: 07-09-2017

Aceptado: 15-02-2019 
